\title{
RECURSOS DIDÁCTICOS PARA LA ENSEÑANZA DE LA HISTORIA DE LA FILOSOFÍA
}

José Eriberto Cifuentes Medina 


\title{
RECURSOS DIDÁCTICOS PARA LA ENSEÑANZA DE LA HISTORIA DE LA FILOSOFÍA*
}

\begin{abstract}
Resumen: la preocupación de los docentes por la enseñanza de la Filosofía ha sido incesante. Prueba de ello lo constituye el diseño de una propuesta que aborda el proceso desde la enseñanza de la Filosofía en la Educación Media. Con la investigación desde el aula se busca resolver problemas de conocimiento para la enseñanza de la Historia de la Filosofía, las escuelas filosóficas y autores de cada época. Se proponen juegos como: parqués filosófico, póker, lotería, ajedrez, tasos, monopolio, tío rico, álbum, diccionario filosófico, bingo, boletín, escalera, domino, vídeos. Estas actividades buscan desarrollar el pensamiento creativo, metódico, razonado, ordenado, abstracto, meditativo, deliberativo y especulativo de los estudiantes.

El desarrollo de recursos didácticos para la enseñanza de la Historia de la Filosofía ha constituido una experiencia de carácter exitoso e innovadora, en la medida que ha ayudado a los educandos de los diferentes niveles a responder de manera eficiente a la vida académica y al examen Saber $11^{\circ}$. Por ello, la pregunta objeto de investigación es: ¿qué estrategia didáctica de mejoramiento podría plantearse para la formación filosófica de los estudiantes de Educación Media a fin de cualificar su aprendizaje y su formación integral?
\end{abstract}

Palabras clave: recursos, didácticos, filosofía, enseñanza.

\section{TEACHING RESOURCES FOR TEACHING THE HISTORY OF PHILOSOPHY}

\begin{abstract}
The concern of teachers for teaching philosophy has been incessant, so that we have designed a proposal that addressed the process from the teaching philosophy of secondary education. Research from the classroom seeks knowledge to solve problems of teaching the history of philosophy and philosophical authors of every age and schools, through games like: philosophical parks, Poker, Keno, Chess, Tasos, Monopoly, rich uncle, Album, philosophical Dictionary, Bingo, Bulletin, Stairs, Domino, Videos; among others in order to develop their creative, methodical, reasoned, orderly, abstract, meditative, deliberative and speculative thought.
\end{abstract}

Developing teaching resources for teaching the history of philosophy has become an experience of successful character has also been innovative as it has helped students of different levels to respond effectively to academic life and the examination of Saber 11th. Therefore the research question is: What educational improvement strategy could arise for the philosophical training of high school students to qualify their learning and comprehensive training?

Keywords: Resources, Teaching, Philosophy, Education.

Fecha de recepción: febrero 2 de 2015

Fecha de aceptación: junio 3 de 2015

Forma de citar: Cifuentes, J. (2015). “Recursos didácticos para la enseñanza de la Historia de la filosofía". Revista Filosofía UIS. 14 (2). pp. 241-279.

José Eriberto Cifuentes Medina: colombiano. Estudiante del Doctorado en Historia, Universidad Pedagógica y Tecnológica de Colombia. Magíster en Educación, Especialista en Educación con énfasis en Evaluación Educativa, Licenciado en Teología, Licenciado en Filosofía y Educación Religiosa, Universidad Santo Tomás. Docente Escuela de Ciencias Administrativas y Económicas FESADUniversidad Pedagógica y Tecnológica de Colombia.

Correo electrónico: joseeriberto.cifuentes@uptc.edu.co

* Artículo de revisión de tema 


\section{RECURSOS DIDÁCTICOS PARA LA ENSEÑANZA DE LA HISTORIA DE LA FILOSOFÍA'}

\section{Introducción}

Los recursos para la enseñanza de la Historia de la Filosofía son significativos en el proceso de enseñanza-aprendizaje en los dos últimos años del bachillerato, es decir, en la Educación Media. Según la Ley 115 de 1994, desde el artículo 27 hasta el 35 se refieren los aspectos relacionados con la educación media académica. Entre las asignaturas "obligatorias y fundamentales las mismas áreas de la Educación Básica en un nivel más avanzado, además de las ciencias económicas, políticas y la Filosofía" (Ley 115, 1994, p. 34, Artículo 29).

La Filosofía ha de ocupar un lugar preponderante en la organización del currículo, por ello en los planes de estudio que por ley se respeta este espacio se ha de considerar oportuno para despertar en los estudiantes su espíritu crítico, reflexivo y analítico. Se han de considerar varias dificultades en el acto educativo: la intensidad horaria, docentes no precisamente todos licenciados en el área, material educativo, compromiso de los estudiantes, entre otros; es necesario buscar oportunidades de mejora y compromisos por alcanzar los objetivos.

Abordar la Historia de la Filosofía desde la óptica constructivista en pro de la construcción de recursos didácticos más afables, más cercanos y familiares para el docente y el estudiante, de manera que no solo contribuya para dar respuesta a las pruebas Saber $11^{\circ}$, sino que, también, aporten a la formación del ser humano sujeto racional y al desarrollo del pensamiento creativo, metódico, razonado, ordenado, abstracto, meditativo, deliberativo y especulativo.

\footnotetext{
${ }^{1}$ El texto, con algunas modificaciones, fue presentado como ponencia en el "X Encuentro de Profesores de Filosofía" "Enseñanza de la filosofía y conflictos en América Latina: Miradas nacionales e internacionales" 06, 07 y 08 de Octubre de 2014, Tunja, Boyacá, en la Universidad Pedagógica y Tecnológica de Colombia.
} 


\section{Consideraciones teóricas}

Se pueden considerar para la presente investigación como categorías teóricas: nociones generales de Didáctica, Pedagogía y Educación, la Filosofía como asignatura, el docente y el estudiante, los recursos didácticos para la enseñanza de la Filosofía en la Educación Media.

\subsection{Nociones generales de didáctica, pedagogía y educación}

En el proceso para entender la importancia de los recursos didácticos para la enseñanza de la Historia de la Filosofía, es pertinente ahondar en conceptos como: Pedagogía, Educación y Didáctica, que se encuentran directamente relacionados hasta el punto que parecieran ser sinónimos, pero existe una posible diferencia entre ellos de manera que una visión general contribuye a inducir la relación entre sí con la filosofía y el acto educativo.

Pedagogía: se podría considerar como una disciplina enfocada al estudio del fenómeno educativo, desde la perspectiva filosófica, científica y técnica, se puede agregar que la: "pedagogía se ocupa de determinar cómo debería llevarse a cabo el proceso educativo... esta perspectiva nos señala el "deber ser" de la educación, una segunda perspectiva —además de la ideal— que es el estudio con fines de conocimiento de su objeto de estudio..." (De la Torre, 2009, p. 13). La pedagogía como disciplina científica, se orienta en dos niveles, a saber:

Tabla 1

\begin{tabular}{cl}
\hline NIVEL DE LA PEDAGOGía & \multicolumn{1}{c}{ DEFINICIÓN } \\
\hline \multirow{2}{*}{ PRIMERO } & Es aquel en el que la Pedagogía se evoca \\
& a la búsqueda de las leyes que expliquen \\
& el fenómeno educativo para efectos de \\
& exponerlo en una teoría, así tenemos a la \\
& Pedagogía como ciencia pura \\
\hline \multirow{3}{*}{ SEGUNDO } & Se puede distinguir cuando la Pedagogía \\
& se inclina al estudio de los problemas de \\
la educación y sus posibles alternativas de \\
solución, así tenemos a la Pedagogía como \\
ciencia aplicada
\end{tabular}

Fuente: Elaboración propia con información de De la Torre (2009).

La Pedagogía es necesaria en la reflexión del acto educativo, en el proceso de enseñanza-aprendizaje de dicha disciplina y en especial de la Historia de la Filosofía, no tanto desde la ciencia pura sino más bien desde la ciencia aplicada. Se estudia un problema de enseñanza-aprendizaje que se refiere a la "Historia de la Filosofía", por ello se invoca la Pedagogía a fin de encontrarle una solución a dicha dificultad a través de esta ciencia desde la perspectiva de buscar alternativas de solución. 
Educación: se podría interpretar como el campo de estudio de la Pedagogía, por eso se puede definir como "el proceso social mediante el cual se trasmiten y preservan los valores y productos culturales, con el fin de que estos se vean enriquecidos y procuren una mejor forma de vida para la sociedad en general y para el individuo en particular" (De la Torre, 2009, p. 14). En relación con la definición se guarda especial relación con el hombre como ser racional, pero, también, social. Por ello, la Educación se apoya de ciencias como: Antropología, Psicología, Sociología; que contribuyen a que el ser humano haga parte de una sociedad y que su formación inicie en la familia, pero que se prolonga en la escuela y continua durante su existencia.

La Educación es tan antigua como la existencia de la misma humanidad, "ya el hombre siempre se preocupó de criar y enseñar a sus hijos... la raíz etimológica del concepto de Educación, que procede del termino latino educare, cuyo significado es criar, alimentar o instruir" (De la Torre, 2009, p.15). La Educación se propone trasmitir a las nuevas generaciones una determinada cultura, conocimientos específicos y preparar al ser humano para un arte o para asimilar las nuevas técnicas, en fin, para que se desenvuelva en la vida.

En la misma Historia de la Educación y desde la antigüedad griega, "la educación se convierte en preocupación principal de los filósofos, que fueron produciendo algunos conceptos relativos al tema, es decir, surgen diversas teorías de la Educación articuladas especialmente con la Historia de la Filosofía, lo que se podría denominar una Filosofía de la Educación: filósofos pensando los problemas de la Educación" (Caicedo, 2010, p. 9). En el desarrollo histórico de la Educación van sucediendo diversas transformaciones del acto o proceso educativo hasta llegar a la modernidad en donde aparece la escuela como institución por excelencia para Educación de grandes masas poblacionales.

El hombre se considera sujeto de educación, y "el ser humano es un peculiar animal de naturaleza racional, social, moral y sentimental. En consecuencia, su educación será el desarrollo lógico de esos rasgos constitutivos. En concreto, el desarrollo correcto de su libertad inteligente será la conducta prudente [...]" (Ramón, 2006, p. 13). Entre tanto la Educación contribuye al desarrollo moral para obrar en conciencia y para vivir en sociedad se requiere de la justicia. Por ello, entre más educado el ser humano, ha de obrar correctamente.

Didáctica: corresponde a "las técnicas que se emplean para manejar de la manera más eficiente y sistemática el proceso enseñanza-aprendizaje. Vinculada a otras ciencias pedagógicas, como la organización escolar y la orientación educativa, la didáctica estudia los procesos de enseñanza -aprendizaje" (De la Torre, 2009, p. 16). Se trata de un proceso conjunto que involucra a la Pedagogía, la Educación y la Didáctica en el acto educativo y su relación con la formación del ser humano en un contexto. 
De este modo, "la Didáctica se puede entender como pura técnica y ciencia aplicada y como teoría o ciencia básica de la instrucción, educación o formación" (De la Torre, 2009, p. 16). En la perspectiva de Gómez (1997), se puede considerar a la didáctica como: “ciencia pedagógico-teórico-práctica es una disciplina que estudia los diversos componentes, humanos y materiales, que intervienen en el proceso de enseñanza-aprendizaje, con el fin de establecer sus funciones e interrelaciones, y dinamizar el acto docente-discente ${ }^{2 \prime}$ (p. 30). En la orientación De la Torre (2009), se puede comprender los componentes del acto didáctico como una posibilidad de comprender la Didáctica:

Figura 1. Componentes del acto didáctico

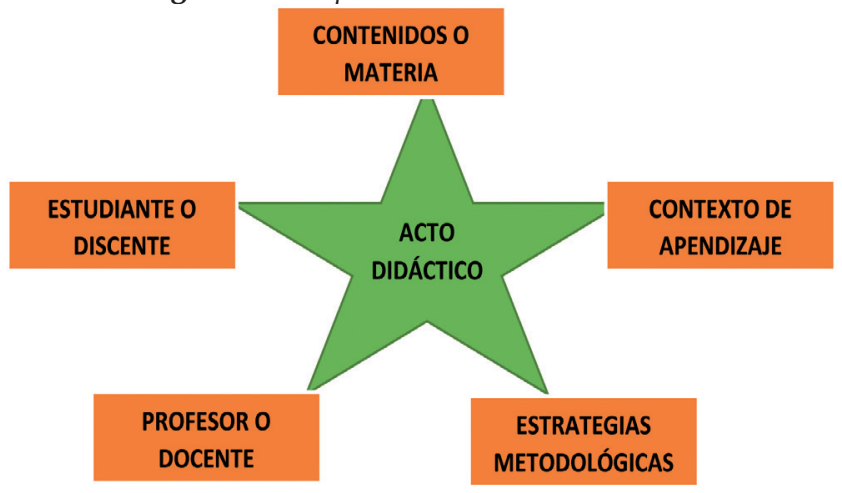

Fuente: elaboración propia

La Didáctica como disciplina particular es "la teoría general del proceso enseñanza-aprendizaje, cuya actividad fundamental es la indagación, descripción, explicación y elaboración del referido proceso" (Islas, 2012, p. 12). Se puede entrelazar la reflexión anteriormente planteada con la siguiente: "la Didáctica, como ciencia y arte de la docencia, debe partir del análisis de nuestras prácticas docentes (lo que hacemos en el aula de clase) para mejorarlas, corregirlas o replantearlas totalmente, según el caso" (Lucio, 2009, p. 14). Los dos atures en mención refieren a la Didáctica como la reflexión y el accionar acerca del proceso enseñanza-aprendizaje, es decir, entre el profesor y el estudiante.

Se hace necesario en el proceso educativo conocer sobre "Pedagogía y Didáctica, [de tal modo que] para un maestro, es saber sobre su hacer, sobre el sentido de sus prácticas, sobre la orientación de lo que en un momento dado se quiere construir como futuro..." (Páez, 2010, p. 18). El maestro se pregunta acerca de sus prácticas para seguir creciendo en pro de ser un mejor pedagogo y orientador de una disciplina, en pro de la construcción de conocimiento.

${ }^{2}$ La palabra discente tiene su origen en el verbo latino disco $=$ yo aprendo. 
Figura 2. Elementos del proceso enseñanza - aprendizaje

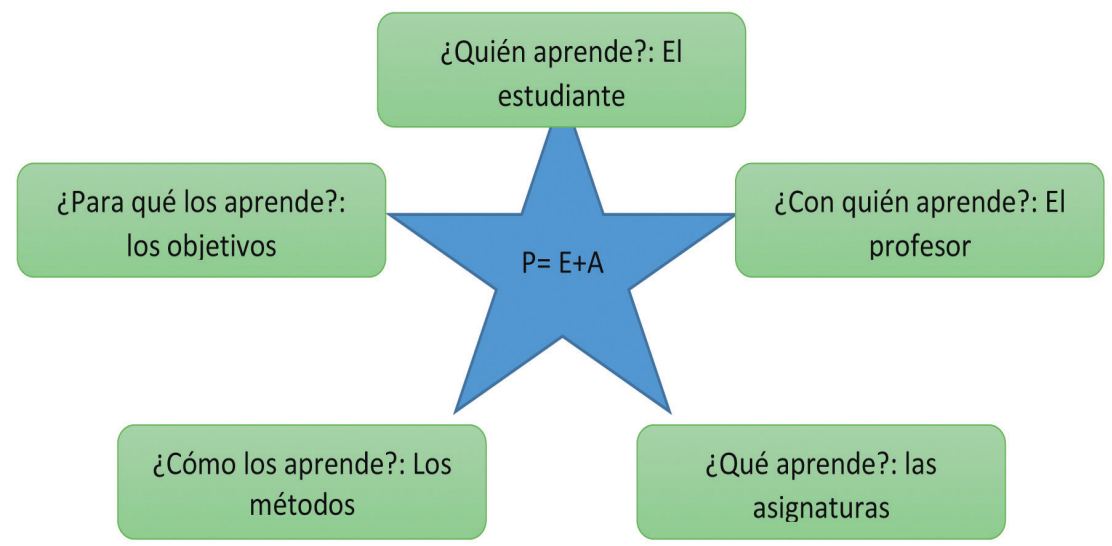

Fuente: elaboración propia

Los elementos del proceso de enseñanza-aprendizaje dan por resultado que el estudiantes "es el centro y sujeto activo del proceso didáctico, el profesor es el guía y el animador del proceso, las asignaturas son el alimento intelectual, los métodos son caminos para alcanzar los objetivos y los objetivos son el blanco perseguido, esto es, el aprendizaje" (Gómez, 1997, pp. 33-35). El acto educativo está encaminado a responder correctamente las preguntas que surgen en concordancia con los actores del proceso.

\section{La Filosofía como asignatura en la Educación Media}

En la Educación Media se continúa y, de manera especial, se profundizan las asignaturas que se viene desarrollando en la Educación Básica, pero se hace necesario abrir un espacio en la Educación Media a la enseñanza-aprendizaje de la Filosofía según el artículo 29: "para el logro de los objetivos de la educación media académica serán obligatorias y fundamentales las mismas áreas de la educación básica en un nivel más avanzado, además de las ciencias económicas, políticas y la filosofía" (Ley 115; 1994, p. 34).

La Educación Media se constituye en la última etapa que el estudiante cursa después de terminar la Básica Secundaria y antes de graduarse de Bachiller. Está comprendida por dos niveles: décimo y undécimo. Se ha establecido, además, que "la educación media académica permitirá al estudiante, según sus intereses y capacidades, profundizar en un campo especifico de las ciencias, las artes o las humanidades y acceder a la educación superior" (Ley 115, 1994, p. 34). 
Es necesario y trascendente acudir a los estudios filosóficos en la enseñanza de la Filosofía en la Educación Media, ya que la escuela no solo tiene por tarea la de instruir sino sobre todo la de educar. Siendo Filosofía amor a la sabiduría, por ello el hombre ha de adoptar una actitud humilde ante el saber y el emprender un camino que le es natural; teniendo en cuenta que el hombre es el único ser intencionalmente educable; "la educación y la filosofía coinciden en cuanto son metas interminables, el proceso educativo del hombre es toda una filosofía, la educación debe preparar al hombre para la vida, como individuo, persona como ser social, la educación debe basarse en una filosofía del hombre" (Gómez, 1997, p. 78). Lo más agradable de entender en este apartado es que la Filosofía contribuye al cultivo del hombre como persona pensante y capaz de pensar en sí mismo a fin de vivir en armonía y equilibrio con su ambiente.

La escuela tiene por tarea iniciar al estudiante en la Filosofía, mediante la reflexión filosófica, es decir, apostándole a filosofar y el filosofar es encontrarle sentido a la vida. Filosofar es razonar, meditar, discurrir con razones filosóficas, filosofar es pensar, actuar con plena conciencia y pasar de un saber vulgar a un saber científico. Por lo tanto, el estudio de la Filosofía en la Educación Media ha de ser una actividad más práctica que teórica, se han de integrar los dos verbos educar y filosofar; no se puede considerar ni antipedagógico y menos perturbadora la enseñanza de la Filosofía en la Educación Media; entre tanto se evidencian algunas objeciones para la enseñanza de la filosofía.

Figura 3. Objeciones para enseñar Filosofía

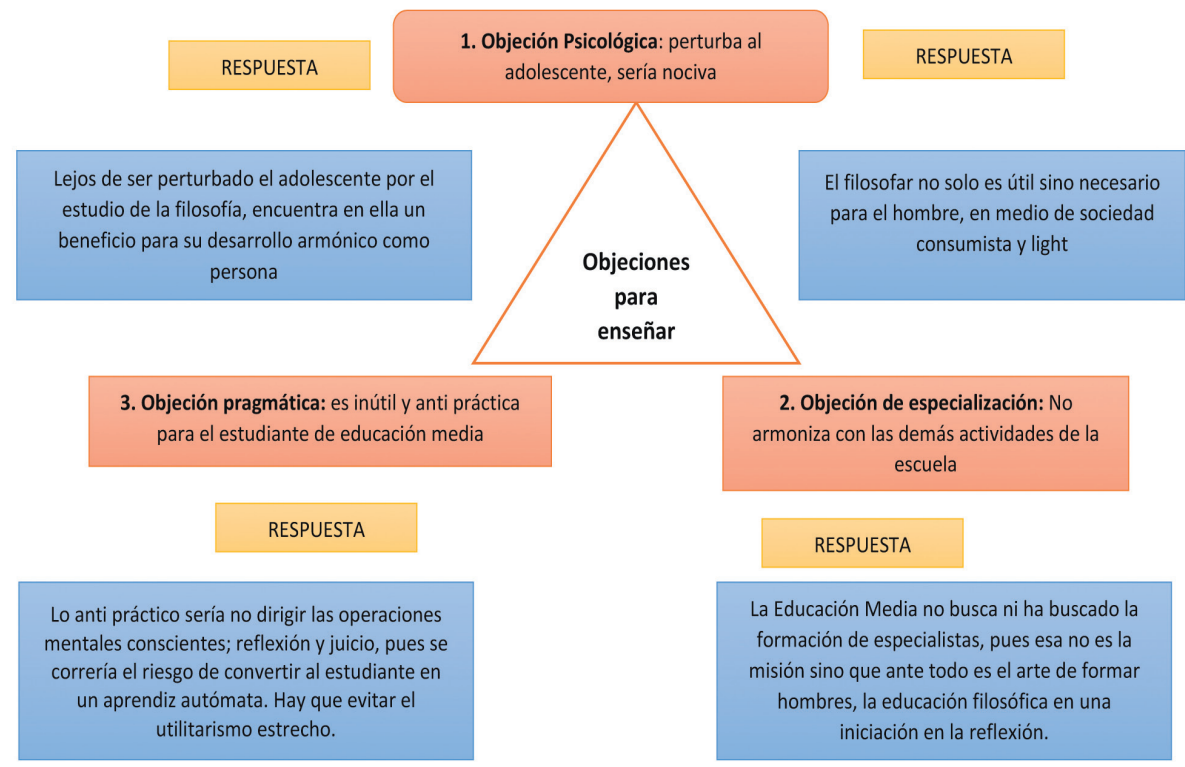

Fuente: elaboración propia basado en Gómez (1997) 
La asignatura de Filosofía esta oficialmente programada en el bachillerato, la legislación educativa la ubica en los dos últimos años, es decir, en la Educación Media pero no impide que se pueda implementar desde la educación básica secundaria, incluso en la educación básica primaria; como ya sucede en algunas instituciones educativas especialmente de carácter privado o bajo la experiencia de Filosofía Para Niños que, por cierto, ha traído buenos frutos.

Los programas no piden el perfecto dominio de todos los problemas filosóficos sino una reflexión sobre las vivencias del estudiante, se puede constituir el estudio de la Filosofía en una iniciación constante dirigida al filosofar; por ello se requiere de un manejo de la cultura general y de la cultura filosófica en la medida que se cultiva el amor por la historia pero también por el arte de filosofar y el comprenderse, como un ser racional y pensante que lo diferencia de los demás seres de la naturaleza.

\section{El docente de Filosofía en la Educación Media}

El profesor, "es la persona que enseña alguna ciencia o arte; es el responsable de orientar y coordinar el proceso de enseñanza-aprendizaje en el aula. Asesora al estudiante mediante el desarrollo de las prácticas y ejercicios que se plantea en el material de estudio..." (De la Torre, 2009, p. 24). Es también:

Agente entre el alumno y la cultura por medio de su propio nivel cultural... un profesor es comparable con un labrador. El labrador que cultiva la tierra debe realizar múltiples acciones: aflojar la tierra, quitar las malas hierbas, sembrar, podar... tales son las responsabilidades del profesor en favor de sus discípulos (23).

El docente que orienta la Filosofía en la Educación Media, "es el otro elemento vivo del proceso enseñanza-aprendizaje y quien, juntamente con el alumno, conforma lo que pudiéramos denominar el binomio humano del hecho educativo. El profesor es el otro elemento didáctico vivo, se le llama: maestro, guía, orientador" (Gómez, 1997, pp. 276-277). Si el conocer para educar es condición indispensable para realizar una labor efectiva, en la docencia, el conocimiento de sí mismo, se evoca a Sócrates "Conócete a ti mismo", invitación diaria a quienes son responsables y promotores de la educación.

Principales dimensiones de un docente de Filosofía: El profesor que orienta Filosofía, requiere partir del hecho de ser persona, si no lo es, difícilmente puede ayudar a la formación de gente comprometida con la institución educativa y con la solución de los problemas que requiere su contexto en educación media. Por ello, urge la propuesta de Recio (2011), al respecto de las dimensiones y cualidades que ha de desarrollar un docente de Filosofía, una primera dimensión corresponde a la formación integral como persona: 
se podrían agregar otras como autoestima, dignidad, hacer uso correcto de la libertad, capacidad de tomar decisiones, seguir sus propios criterios, honestidad, ética, capacidad de escucha, apertura, mente abierta, respeto por las ideas ajenas, tolerante, compañero del proceso de aprendizaje del alumno y exige, pero dando mucho de sí mismo (Recio, 2001, p. 25).

En la enseñanza de la Filosofía, según Lozano (2011) el verdadero y auténtico profesor ha de ser prudente y sabio, en el ejercicio de su labor, ha de estar asistido por cualidades de persona integral y le es necesario desarrollar un equilibrio de doce dimensiones para brindar un servicio de calidad a sus estudiantes.

Figura 4. Dimensiones de un docente

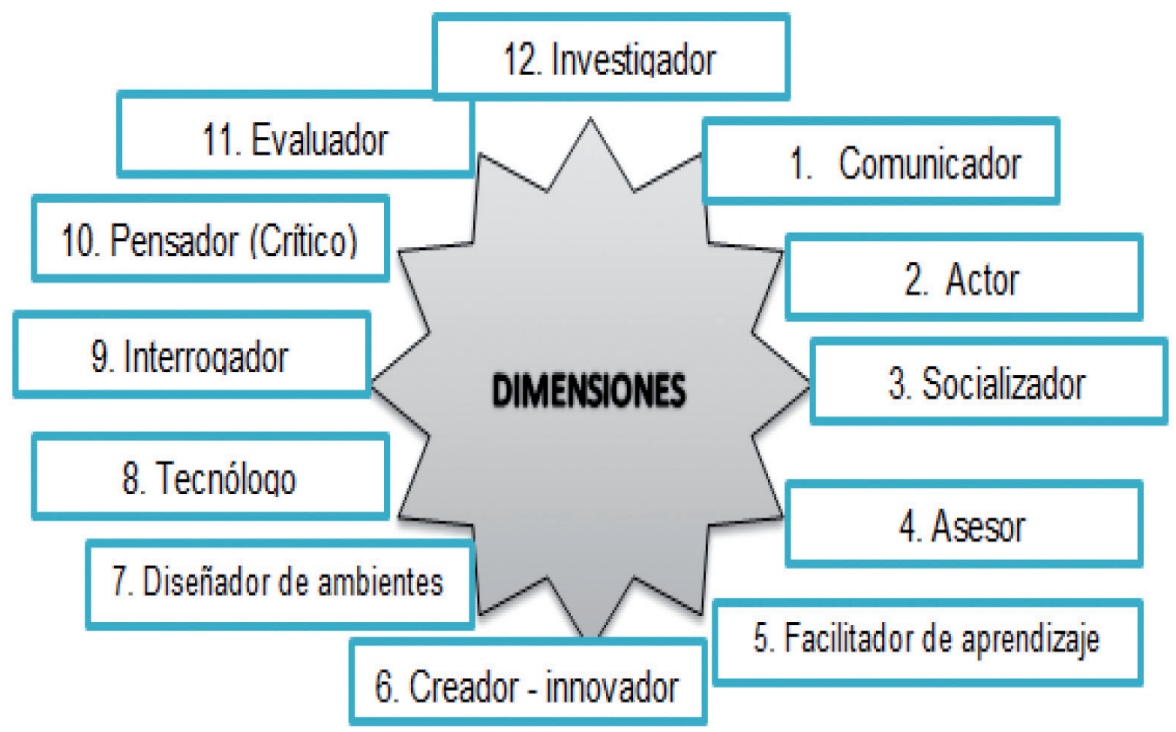

Fuente: elaboración propia con información de Recio (2011) y Lozano (2011).

Los docentes del siglo XXI que desempeñan su labor en la enseñanza de la Filosofía requieren de una preparación idónea y de cualificación permanente acordes a la vanguardia de los avances tecnológicos propios de la época. El docente ha de ser un excelente comunicador, "es imposible no comunicar, todo lo comunica y toda la comunicación tiene múltiples significados..." (Lozano, 2011, p. 19). Ahora se evidencia en la perspectiva de Gómez (1997): 
Figura 5. Un docente en la Educación Media

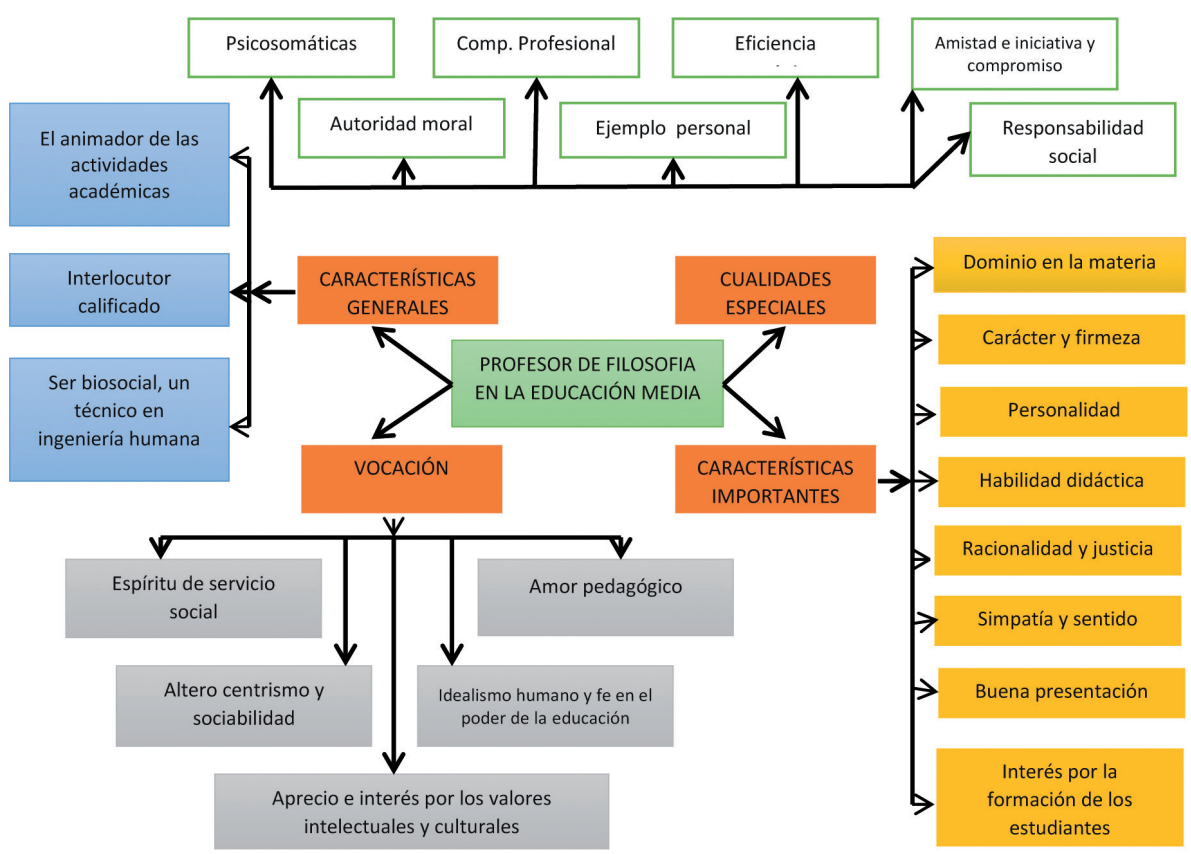

Fuente: Gómez (1997, pp. 277ss.)

El profesor de Filosofía es, ante todo, un profesor y su común denominador ha de ser docente que lo identifique y lo ubique en el contexto didácticopedagógico. Por ello, el profesor ha de ser: "interlocutor calificado, el animador de las actividades académicas, un ser biosocial, un técnico en ingeniería humana y con vocación de docente: inclinación hacia el magisterio; con un conjunto de predisposiciones afectivas, con espíritu de servicio social y complacencia personal" (Gómez, 1997, pp. 278-281). La vocación es la base fundamental de su profesión y ha de contar con cualidades especiales que, en definitiva, constituyan el signo del hombre culto y ha de cultivarse y perfeccionarse continuamente en el tiempo.

El profesor de la asignatura de Filosofía debe ser un educador especial, dotado de cualidades particulares: amor a la Filosofía, profundidad de pensamiento, dinámica mental, honestidad intelectual, compromiso con la verdad, cultura filosófica, cultura general, madurez y experiencia, claridad de expresión, habilidad comunicativa, entre otras. 
Figura 6. Cualidades de un profesor de Filosofía

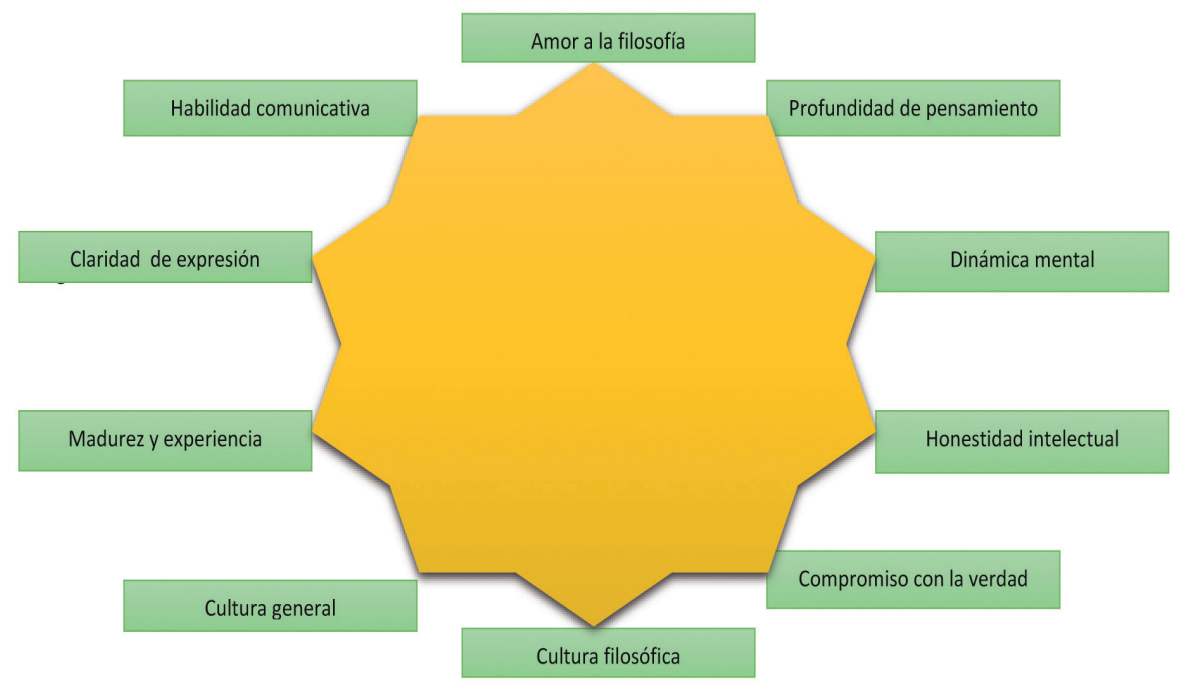

Fuente: Gómez (1997,pp. 293ss.)

La acción del profesor de Filosofía tiene múltiples y variadas posibilidades para que de su fruto, que debe contar no únicamente con su propia inspiración sino también con la actividad de los mismos estudiantes y con otros medios distintos de él y de ellos, pueda lograr optimizar y dinamizar las deliberaciones de Filosofía y lograr de manera didáctica aprehender la Historia de la Filosofía.

Competencias de un docente de Filosofía: la Ley 115 de 1994, plantea dentro de los principios de la educación, "la formación integral, la cual debe traducirse en la preparación de profesionales no solo instruidos, especializados y competentes, sino que sean personas integrales con una alta calidad humana y comprometidos con el proceso de construcción reconstrucción nacional" (Morales, 1999, p. 10).

El docente que orienta la asignatura de Filosofía, además de apropiarse de las dimensiones que propone Lozano (2011), Recio (2001) y Gómez (1997), le es pertinente desarrollar cinco competencias que según De la Torre (2009) y Corrales (2008) se pueden constituir en pilares fundamentales en el ejercicio de su labor pedagógica con calidad y eficiencia. A continuación se presentan de manera prudente cinco competencias que un docente ha de fomentar en la vida académica: 
Figura 7. Competencias de un docente de Filosofía

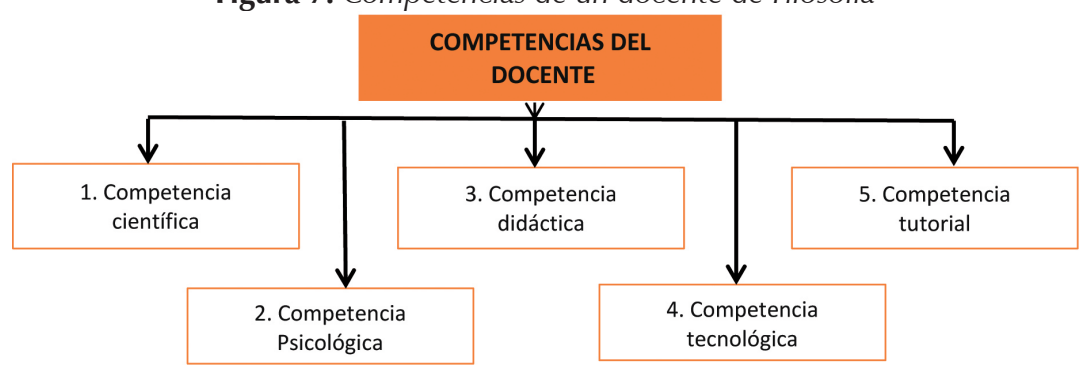

Fuente: elaboración propia

El docente es un "experto en la materia que ha de enseñar, así mismo conoce y cuestiona el pensamiento espontáneo y adquiere conocimientos relacionados con el aprendizaje de las ciencias" (De la Torre, 2009, p. 25). En lo didáctico se refiere a la aptitud o suficiencia para transmitir conocimientos; el docente ha de dominar las técnicas y métodos de enseñanza habitual, despertar la innovación e interacción con el estudiante, al igual que un adecuado equilibrio psicológico. Su competencia psicológica ha de servir para captar los sentimientos de los demás y saberlos tratar como personas, en beneficio de la construcción de un tejido social proactivo.

\section{El estudiante de Filosofía en la Educación Media}

El estudiante o "educando es quien recibe educación en una institución de enseñanza de cualquier nivel; es el actor principal del proceso de aprendizaje, que debe asumir un papel activo y responsable en la consecución de los propósitos planteados en el programa de la asignatura" (De la Torre; 2009, p. 23).

Desde la perspectiva de Gómez (1997) se argumenta que "el alumno es el centro y sujeto activo de la educación, esta es una conclusión de la revolución copernicana pedagógica, el alumno es la principal justificación de la docencia, el alumno en la enseñanza media es un adolescente, el adolescente es el individuo que crece, que madura" (pp. 198-200). Se constituye el periodo de la adolescencia tiempo en el que cursa el sujeto su Educación Media, este tiempo es un periodo de crecimiento en todo el sentido de la palabra y también de maduración, considerándose un periodo inestable pero también transitorio, época del redescubrimiento del yo, del nacimiento de la intimidad y de la autoafirmación de la personalidad.

Desde la perspectiva del enfoque constructivista, el estudiante ha de ser "un procesador activo que relaciona la información nueva por aprender, con su 
estructura cognitiva, de manera no arbitraria ni al pie de la letra, logrando con ello un aprendizaje significativo" (De la Torre, 2009, p. 23). Por ello, el educando es una persona activa y dinámica en el proceso de aprendizaje, en la aprehensión de nuevas realidades y en la construcción de conocimiento.

Figura 8. El estudiante de Filosofía

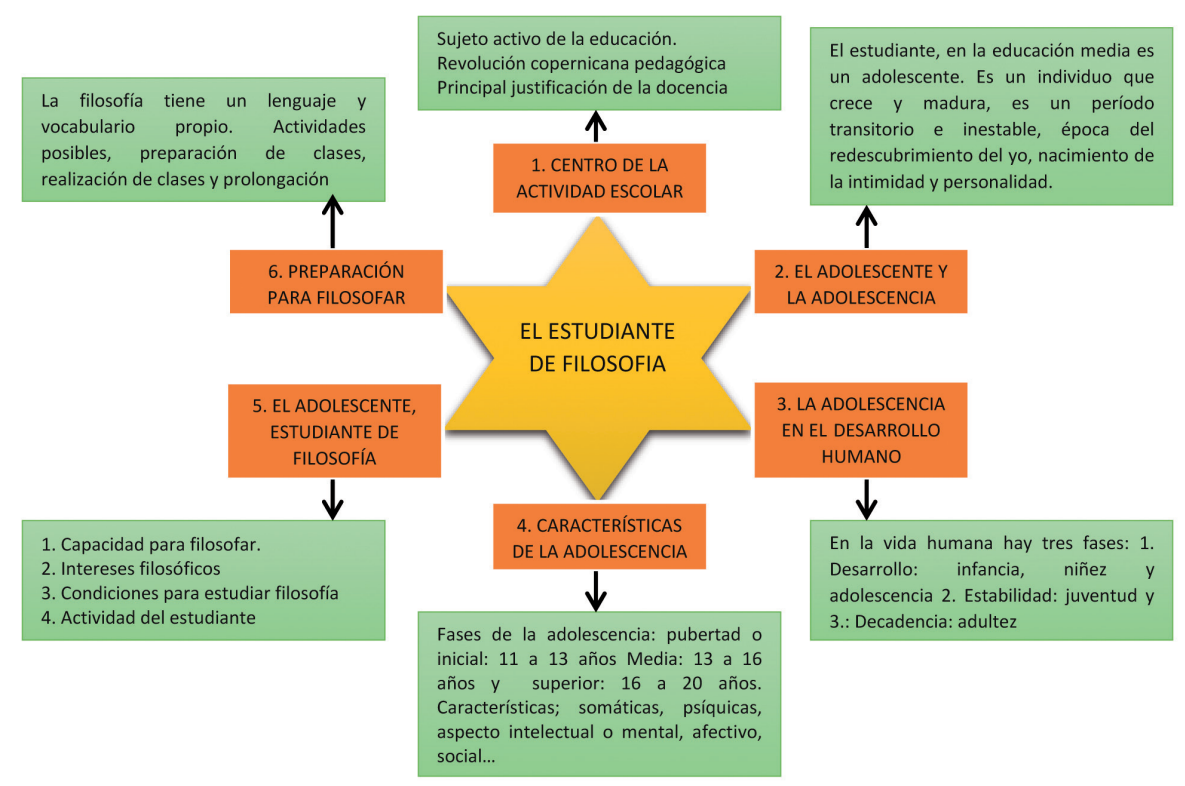

Fuente: elaboración propia

La mayor parte de estudiantes de Filosofía actualmente se encuentran en la adolescencia media y algunos en la superior; por ello se determina que:

las facultades mentales del adolescente son aptas para filosofar, el desarrollo mental posibilita la confrontación con la Filosofía, los primeros principios están ya arraigados, la dialéctica es abierta, la Filosofía despierta su propia motivación, los intereses implícitos son decisiones latentes, tendencias al saber y los intereses explícitos son decisiones voluntarias de salir de la ignorancia (Gómez, 1997, pp. 216- 218).

Los estudios filosóficos son necesarios al joven, como reactivo y alimento de su inteligencia. La apatía de los estudiantes por la Filosofía se da muchas veces por el profesor: no es aceptado, es incompetente, falto de metodología, no es profesional en la asignatura, entre otros aspectos propios de un profesor no apto o idóneo para la enseñanza de la Filosofía, que preocupa a la educación. 
Son condiciones necesarias para estudiar Filosofía: "conocimientos previos, si los estudios anteriores han sido flojos, tendremos un primer escollo para la Filosofía, si han sido sólidos, el alumno encontrará en la Filosofía nuevos estímulos y nuevos horizontes, las deficiencias lingüísticas son otro obstáculo para la Filosofía" (Gómez, 1997, pp. 220- 222). De igual talante es necesario comprender el giro copernicano pedagógico, ya no es el docente el centro del proceso como sucedía en la escuela tradicional en donde era un receptor pasivo, en la pedagogía de los tiempos actuales el estudiante se ha convertido en el principal factor del aprendizaje.

Por los avances de la ciencia y la tecnología, el estudiante es activo, pero también es autodidacta. Por ello, la Filosofía es una de las asignaturas más aptas para despertar la actividad académica del estudiante, pues aprende más por lo que él mismo hace o dice y ha de tomar conciencia de la necesidad de su participación activa en la clase de Filosofía.

El profesor ha de promover actividades posibles para un desarrollo excelente de su clase de Filosofía como: "individuales, grupales, previas a la clase, durante la clase, posteriores, lectura y comentario, trabajos escritos, exposiciones, diálogos, debates, dinámicas, cine-foro, evaluaciones, investigaciones. El alumno debe preparar la clase para aprovecharla mejor, esto el evitara presentarse a ciegas y le permitirá participar activamente" (Gómez, 1997, pp. 226-228). El docente ha de facilitar y ofrecer garantías de participación activa al estudiante para que él le ponga su sello e impronta personal; pues la Filosofía se presta para que sea una clase magistral que en ocasiones conviene, pero no hay que abusar de ella, pues el estudiante puede sentirse ausente, distraerse, promover la indisciplina y hasta sentir fobia por la clase de Filosofía.

\section{Recursos didácticos y metodología para la enseñanza de la Filosofía}

En el proceso teórico en el que se ha avanzado, nos adentramos en los recursos didácticos en pro de obtener los resultados esperados por parte de los profesores y de los estudiantes en la asignatura Filosofía.

Conviene realizar una aclaración entre método, metodología y método didáctico desde la perspectiva de Gómez (1997). Para este autor, "método significa: según un camino... una dirección... existen métodos: lógicos, psicológicos y didácticos. Lógicos, son utilizados por la Filosofía y las ciencias, son propios de los filósofos. Psicológicos van del plano del objeto (verdad) al plano del sujeto (aprendiz)" (pp. 40- 41). Los métodos didácticos son la mezcla de los anteriores y se llaman psicopedagógicos por cuanto contribuyen al desarrollo del proceso enseñanza-aprendizaje. 
La relación de método como camino y metodología como: "el estudio de los diferentes caminos para descubrir la verdad, enseñarla y hacerla aprender. Se habla en este contexto de: método heurístico, didáctico y de estudio. El método didáctico o método de enseñanza es conjugación de los diversos caminos para enseñar y para aprender" (Gómez, 1997, pp. 41-43). La tarea de enseñar es hacer aprender metódicamente, de manera que el proceso de organización racional y práctica de los recursos y procedimientos del profesor, con el propósito de dirigir el aprendizaje de los estudiantes hacia los resultados deseados y obtener dominio seguro de la asignatura.

Figura 9. Método, metodología y método didáctico

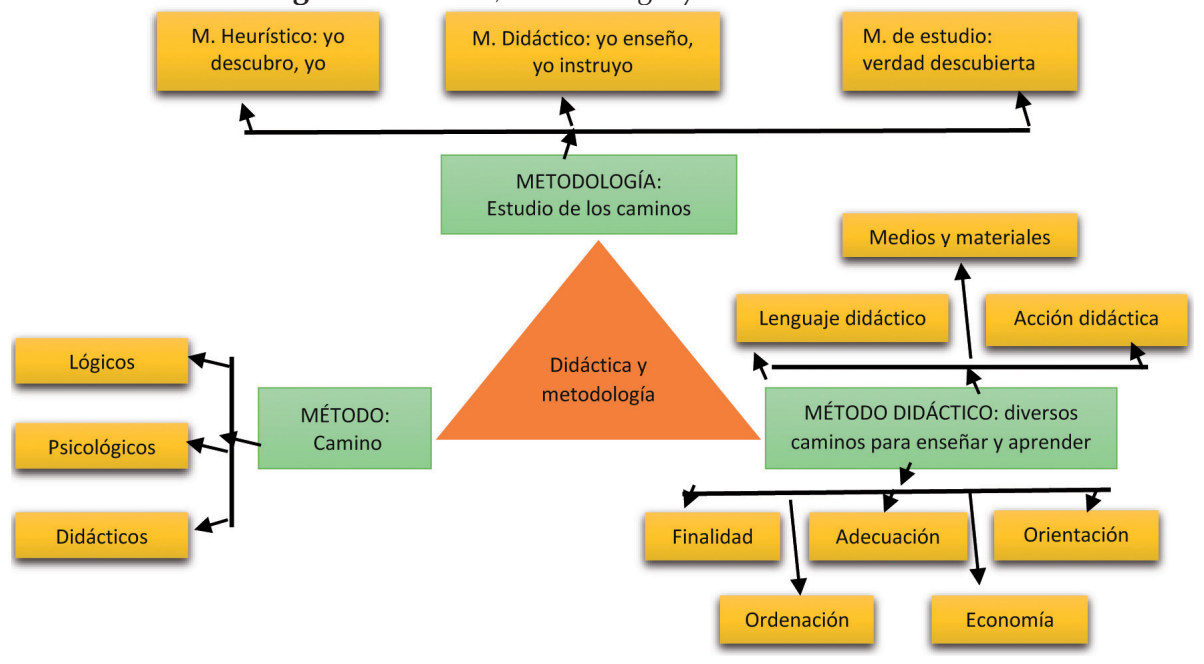

Fuente: elaboración propia

En la medida que se ha estudiado, el método, la metodología y el método didáctico se entrelazan con los recursos didácticos como una posibilidad de hacer más ameno el proceso de enseñanza-aprendizaje, de manera que "denominamos medios y recursos didácticos a todos aquellos instrumentos que, por una parte ayudan a los formadores en su tarea de enseñar y por otra, facilitan a los alumno el logro de los objetivos de aprendizaje" (Corrales, 2008, p. 189). Se ha de pensar en los recursos didácticos de acuerdo al grupo, el presupuesto, el tiempo, las características de cada recurso, conocimientos previos y del desarrollo educativo.

Es ineludible que las clases se desarrollen de manera metódica, didáctica. De tal modo que no se debe perder de vista que "la enseñanza de la filosofía pide un método didáctico, el método didáctico en filosofía no es totalmente independiente del método del conocimiento, hay que llegar al punto de conjunción de lo científico con lo didáctico" (Gómez, 1997, pp. 347-349). La metodología didáctico-filosófica es combinación y articulación de métodos, formas y técnicas de enseñanza. 
Entre los métodos generales, se destacan el de inducción y deducción, por este lado pues estar el núcleo central de la metodología con el análisis y la síntesis son el camino de ida y vuelta del pensamiento;

La inducción o razonamiento inductivo, es el método general que partiendo de algo particular o menos universal conduce el pensamiento a algo universal o más universal. La inducción va de lo general a lo particular. La deducción se contrapone a la inducción pero la complementa para formar un ciclo didáctico. La deducción en la enseñanza va precedida por la inducción y a la vez puede servirle de precedente (Gómez, 1997, pp. 351-355).

La intuición es una forma de enseñanza-aprendizaje, de manera que contribuye a ponerle freno al verbalismo magistral y sirve de auxiliar al discurso docente, de manera que la intuición es la base de la instrucción.

La exposición ha de ser combinada, dosificada y equilibrada, esta consiste en la representación oral de un tema y hay diferentes modalidades de exposición: "el discurso y la conferencia, la narración, la descripción, la explicación y es exposición filosófica: el discurso crítico-fundamentador, el discurso iluminador y las cualidades exigibles son: precisión, división en partes, ordenación lógica, temas motivadores, ejemplificación, aplicación al alumno" (Gómez, 1997, pp. 363366). El estudiante ha de exponer formulando y analizando problemas filosóficos, presentando tesis filosóficas, manifestando grandes líneas de doctrina o sistema filosófico, presentando un estado actual de la cuestión, iluminando el sentido del acontecimiento según corresponda el estado de la Filosofía. La exposición tiene ventajas y desventajas:

Tabla 2. Ventajas y desventajas de la exposición en Filosofía

VENTAJAS

Unidad, orden, adaptación a los estudiantes, tratamiento de todos los temas, posibilidad de trabajar con clases numerosas, posibilidad de escuchar los postulados de los estudiantes

\section{DESEVENTAJAS}

Que se pueda dar pasividad, posible divorcio de conciencias, que queden posibles deficiencias o vacíos en los estudiantes, que se prepare y aprenda el tema, solo memoria por la exposición sin análisis argumentativo

Fuente: elaboración propia

Desde la perspectiva de Gómez (1997), "la interrogación involucra al alumno en su propio aprendizaje de manera personal y directa, es criticada por algunos pedagogos y alabada por otros, consiste en una actividad coloquial de preguntas y respuestas, refuerza y aviva la exposición" (pp. 370-373). Existen diversas clases y tipos de preguntas: orales, escritas, cerradas, abiertas, efectiva, retoricas, lingüistas, lógicas, epistemológicas, críticas, ontológicas y metafísicas. 
El uso diversificado de las preguntas lleva a que el estudiante vea la asignatura de Filosofía como posibilidad de razonamiento y construcción de conocimiento, apoyado de igual manera en métodos como el socrático: conversación socrática o diálogo que consiste en la comunicación docente-estudiante mediante preguntas y respuestas y se ha de avanzar en preparar al estudiante para realizar lectura, análisis y comentario de los textos filosóficos.

\section{Propuesta de trabajo}

La propuesta en el presente artículo aborda tres partes a saber: la primera en relación al programa o plan de estudios de la asignatura de Filosofía para Educación Media de los grado décimo y undécimo en dirección a la Historia y campos de la Filosofía, la segunda guarda relación a las sugerencias de algunos textos o materiales impresos para la enseñanza de la Filosofía y una tercera a unos recursos didácticos que se podrían implementar y a otros que se han implementado en el proceso de enseñanza-aprendizaje de la Filosofía.

\subsection{Primera parte: Organización del plan de estudios}

La propuesta del plan de estudios se ajusta a al presente artículo en dirección de proponer recursos para la enseñanza de la Historia de la Filosofía en el marco de la Educación Media, se define en diez puntos e inmediatamente la distribución temática por periodos en décimo y undécimo.

Tabla 3. Propuesta para la organización del plan de estudios para la Filosofía de $10^{\circ}$ y $11^{\circ}$

\begin{tabular}{|c|c|c|}
\hline $\mathbf{N}^{\circ}$ & ITEM & DEFINICIÓN \\
\hline 1. & IDENTIFICACIÓN & $\begin{array}{l}\text { Corresponde a la ubicación espacio-temporal de la } \\
\text { asignatura en lo referente a: Institución educativa, } \\
\text { dirección, municipio, departamento, rector (a), } \\
\text { coordinador (a) académico (a), jefe de área, entre otros. }\end{array}$ \\
\hline 2. & JUSTIFICACIÓN & $\begin{array}{l}\text { Responde a la pregunta ¿para qué?, se diseña el plan } \\
\text { de estudios, según el contexto en el que se desarrolla el } \\
\text { proceso de enseñanza-aprendizaje de la Filosofía. }\end{array}$ \\
\hline 3. & MARCO TEÓRICO & $\begin{array}{l}\text { Se constituye en el soporte teórico y los referentes } \\
\text { al respecto de autores en los aspectos de Pedagogía, } \\
\text { Didáctica y Filosofía se refieren y que le aporten con bases } \\
\text { sólidas al plan de estudios y desde luego al docente y al } \\
\text { estudiante como centro del proceso educativo. }\end{array}$ \\
\hline 4. & $\begin{array}{l}\text { OBJETIVO } \\
\text { GENERAL }\end{array}$ & $\begin{array}{l}\text { Es el planteamiento de la meta general a lograr en } \\
\text { el proceso de enseñanza-aprendizaje y puede ir } \\
\text { acompañado de objetivos específicos o metas cortas de } \\
\text { manera que ayuden a lograr la meta. }\end{array}$ \\
\hline
\end{tabular}




\begin{tabular}{|c|c|c|}
\hline 5. & $\begin{array}{l}\text { DISTRIBUCIÓN } \\
\text { TEMÁTICA }\end{array}$ & $\begin{array}{l}\text { La distribución temática es relativa y depende desde el } \\
\text { punto de vista incluso de los directivos del colegio, de } \\
\text { la mirada del docente, las referencias textuales; en fin, } \\
\text { es diversa y se enmarca en un pluralismo de donde el } \\
\text { docente con el apoyo de textos y documentos construye } \\
\text { el propio teniendo en cuenta el contexto social, cultural y } \\
\text { educativo de los educandos. }\end{array}$ \\
\hline 6. & RECURSOS & $\begin{array}{l}\text { Se refiere a los recursos que se requieren como: humanos, } \\
\text { docente-estudiantes y principalmente demás actores del } \\
\text { proceso. Recursos físicos como la planta física y demás } \\
\text { necesarios para el proceso de enseñanza-aprendizaje al } \\
\text { igual que los recursos didácticos. }\end{array}$ \\
\hline 7. & $\begin{array}{c}\text { ESTRATEGIAS } \\
\text { METODOLÓGICAS }\end{array}$ & $\begin{array}{l}\text { Son todas aquellas herramientas que le permiten al } \\
\text { docente y también al estudiante dinamizar y sintonizar } \\
\text { el proceso educativo de enseñanza-aprendizaje de la } \\
\text { Filosofía en la Educación Media. }\end{array}$ \\
\hline \multirow{6}{*}{8.} & \multirow{6}{*}{$\begin{array}{c}\text { SISTEMA } \\
\text { DE EVALUACIÓN }\end{array}$} & $\begin{array}{l}\text { Formación cognitiva: se tiene en cuenta la escala de } \\
\text { evaluación según el proyecto de evaluación institucional } \\
\text { (Decreto 1290) escala desde 0.5 A 5.0. La tabla de } \\
\text { valoraciones es: }\end{array}$ \\
\hline & & VALORACIÓN \\
\hline & & Desempeño Bajo( Bj) \\
\hline & & Desempeño Básico( Bs) \\
\hline & & Desempeño Alto (A) \\
\hline & & Desempeño Superior( S) \\
\hline 9. & $\begin{array}{l}\text { ACTIVIDADES DE } \\
\text { EVALUACIÓN }\end{array}$ & $\begin{array}{l}\text { Son todas aquellas que permiten afianzar el proceso } \\
\text { de enseñanza-aprendizaje, en donde está en juego los } \\
\text { recursos, medios y estrategias didácticas, los que serán } \\
\text { algunos de ellos: exposiciones, debates, cine-foro y el uso } \\
\text { de los diversos organizadores gráficos enunciados. }\end{array}$ \\
\hline 10 & BIBLIOGRAFÍA & $\begin{array}{l}\text { Se ubica los diferentes textos y referentes de consulta, a } \\
\text { manera de bibliografía e infografía en orden alfabético y } \\
\text { siguiendo las normas de citación APA, de igual manera las } \\
\text { referencias bibliográficas. }\end{array}$ \\
\hline
\end{tabular}

Fuente: elaboración propia

Los aspectos precedentemente ostentados, son lineamientos generales para la formulación de un plan de estudios para la asignatura de Filosofía en la Educación Media, y en la siguiente tabla se presentan los temas a desarrollar por periodos en $10^{\circ}$ y $11^{\circ}$ respectivamente, sin descuidar la propuesta de la enseñanza de la Historia de la Filosofía. A continuación, se evidencia una propuesta de organización del programa académico o plan de estudios para la asignatura de Filosofía: 
Tabla 4. Propuesta de plan de estudios para la Filosofía de $10^{\circ}$

\begin{tabular}{|c|c|c|}
\hline \multicolumn{2}{|c|}{ ASIGNATURA: FILOSOFÍA } & GRADO: DÉCIMO \\
\hline PERIODO & TEMA GENERAL & SUBTEMAS \\
\hline PRIMERO & $\begin{array}{l}\text { GENERALIDADES DE } \\
\text { LA FILOSOFÍA }\end{array}$ & $\begin{array}{l}\text { Concepto y origen de la Filosofía. } \\
\text { ¿Para qué sirve la Filosofía? } \\
\text { División y relación con otras ciencias. } \\
\text { Filosofía: objeto y sus métodos. }\end{array}$ \\
\hline SEGUNDO & $\begin{array}{l}\text { FILOSOFÍA ORIENTAL } \\
\text { Y ANTIGUA }\end{array}$ & $\begin{array}{l}\text { Generalidades y división Oriental. } \\
\text { Budismo, Confucionismo, Taoísmo e } \\
\text { Hinduismo. } \\
\text { Generalidades y división de la Filosofía } \\
\text { Antigua. } \\
\text { Filosofía Pre ática: diferentes escuelas } \\
\text { Filosofía Clásica: Sócrates, Platón y Aristóteles } \\
\text { Filosofía helenístico-romana. }\end{array}$ \\
\hline TERCERO & $\begin{array}{l}\text { FILOSOFÍA } \\
\text { MEDIEVAL Y } \\
\text { MODERNA }\end{array}$ & $\begin{array}{l}\text { Generalidades y división de la Filosofía } \\
\text { Medieval. } \\
\text { Filosofía Patrística. Filosofía árabe y judía. } \\
\text { Filosofía Escolástica. Filosofía de la decadencia } \\
\text { de la escolástica. } \\
\text { Generalidades y división de la Filosofía } \\
\text { Moderna. } \\
\text { Humanismo renacentista, Revolución política, } \\
\text { religiosa y científica, Racionalismo. Empirismo, } \\
\text { Criticismo, Ilustración, Idealismo. }\end{array}$ \\
\hline CUARTO & $\begin{array}{l}\text { FILOSOFÍA } \\
\text { CONTEMPORANEA Y } \\
\text { LATINOAMERICANA }\end{array}$ & $\begin{array}{l}\text { Generalidades y división de la Filosofía } \\
\text { Contemporánea. } \\
\text { Positivismo, Materialismo, Utilitarismo, } \\
\text { Evolucionismo, Pragmatismo, Existencialismo } \\
\text { Vitalismo } \\
\text { Generalidades y división de la Filosofía Actual. } \\
\text { Problemas actuales: (tecnología, Dios...) } \\
\text { La escuela de Frankfurt. } \\
\text { Generalidades y división de la Filosofía } \\
\text { Latinoamericana. Representantes y } \\
\text { pensamiento. }\end{array}$ \\
\hline
\end{tabular}

Fuente: elaboración propia 
Tabla 5. Propuesta de plan de estudios para la Filosofía de $11^{\circ}$

\begin{tabular}{|c|c|c|}
\hline \multicolumn{2}{|c|}{ ASIGNATURA: FILOSOFÍA } & GRADO: UNDÉCIMO \\
\hline PERIODO & TEMA GENERAL & SUBTEMAS \\
\hline PRIMERO & $\begin{array}{l}\text { FILOSOFÍA } \\
\text { COLOMBIANA. } \\
\text { ONTOLOGÍA, } \\
\text { EPISTEMOLOGÍA Y } \\
\text { LÓGICA }\end{array}$ & $\begin{array}{l}\text { Generalidades y división de la Filosofía Colombiana. } \\
\text { Periodos y representantes. } \\
\text { ONTOLOGíA: Origen e inicio. En la Edad Media } \\
\text { y reflexión Moderna. Pensamiento ontológico } \\
\text { contemporáneo y actual. } \\
\text { EPISTEMOLOGíA: en las diversas épocas. } \\
\text { LÓGICA: características y conceptos generales. } \\
\text { La lógica como estructura del pensamiento } \\
\text { La lógica en la Edad Media y la revolución en la } \\
\text { edad moderna. Presente de la Lógica. } \\
\text { ¿Qué es el conocimiento y cómo se conoce? } \\
\text { Orientación e intencionalidad del conocimiento. } \\
\text { Criterio de validez del conocimiento en la } \\
\text { modernidad y en la actualidad. }\end{array}$ \\
\hline SEGUNDO & $\begin{array}{l}\text { ANTROPOLOGÍA, } \\
\text { COSMOLOGÍA Y } \\
\text { SOCIOLOGÍA }\end{array}$ & $\begin{array}{l}\text { ANTROPOLOGíA: la pregunta por el hombre y } \\
\text { el hombre en el medioevo. El hombre como ser } \\
\text { pensante, social, como persona y ser total. } \\
\text { COSMOLOGíA: primera explicaciones. Forma y } \\
\text { constitución del universo. El desarrollo de las ciencias } \\
\text { y el concepto de mundo hoy. Conceptos básicos de } \\
\text { la Sociología. Aproximación a la Sociología. }\end{array}$ \\
\hline TERCERO & $\begin{array}{l}\text { ÉTICA, AXIOLOGÍA, } \\
\text { ESTÉTICA Y } \\
\text { SOCIOPOLÍTICA }\end{array}$ & $\begin{array}{l}\text { ÉTICA: sentido y quehacer de la Ética. } \\
\text { La virtud, la Filosofía. Éticas autónomas, heterónomas } \\
\text { y de la responsabilidad. } \\
\text { AXIOLOGÍA: origen del valor, los valores y las } \\
\text { teorías. } \\
\text { Sentido de los valores y nuevos valores. } \\
\text { ESTÉTICA: la reflexión filosófica de la Estética, } \\
\text { expresiones artísticas. } \\
\text { SOCIOPOLÍTICA: la reflexión acerca del arte } \\
\text { de gobernar. Los sistemas políticos y los partidos } \\
\text { políticos. }\end{array}$ \\
\hline CUARTO & $\begin{array}{l}\text { PSICOLOGÍA Y } \\
\text { FILOSOFÍA DE LA } \\
\text { RELIGIÓN }\end{array}$ & $\begin{array}{l}\text { PSICOLOGÍA: la concepción de la Psicología como } \\
\text { ciencia. Teorías y corrientes Psicológicas. } \\
\text { FILOSOFÍA DE LA RELIGIÓN: el ser humano como } \\
\text { ser religioso. Lo religioso como problema filosófico. } \\
\text { Aproximaciones filosóficas al hecho religioso. } \\
\text { Sentido y función del aspecto religioso en la vida } \\
\text { humana. }\end{array}$ \\
\hline
\end{tabular}

Fuente: elaboración propia 


\section{2. Segunda parte: Textos para la enseñanza de la Filosofía}

En la labor docente y para confrontar el proceso de enseñanza, se acude a diversos textos impresos. A continuación, se exponen la existencia de algunos y se intenta hacer un análisis de cada uno de ellos con sus posibles ventajas y desventajas como herramientas docente, haciendo hincapié en el desarrollo de la historia de la Filosofía. Son textos que contribuyen a ilustrar el desarrollo del artículo y soportar la documentación que auxilian la labor docente y también del estudiante.

Imagen 1. Libros de Filosofía

Cada uno de los textos presenta tres
unidades de trabajo para décimo.
Primeraunidad: naturalezayrelaciones
de la Filosofía (ámbito histórico);
segunda Unidad: instrumento del
filosofar (ámbitos Lógico, gnoseológico
y epistemológico) y tercera unidad:
horizonte del filosofar (ámbito
metafísico u ontológico).

Fuente: editorial Paulinas

Son textos editados por la editorial Paulinas y están diseñados para la Educación Media en los dos niveles: décimo y undécimo respectivamente, facilitando un proceso de enseñanza-aprendizaje de la Filosofía, en el proceso apoyado en la formación por competencias. 
Imagen 2. Libros de Filosofía

\begin{tabular}{|c|l|}
\hline Pensemos 11 & $\begin{array}{l}\text { El texto de Pensemos } 11^{\circ} \text { está en } \\
\text { dirección de trabajar los siguientes } \\
\text { temas: cosmología, la ciencia, } \\
\text { Epistemología, Ontología, Filosofía } \\
\text { de la Religión, Axiología, Ética y } \\
\text { Sociología; presentando en sílos temas } \\
\text { de manera elemental para el desarrollo } \\
\text { de la Filosofía en la Educación Media } \\
\text { de manera que se establezcan pautas } \\
\text { para la aprehensión de herramientas } \\
\text { para el filosofar de los estudiantes. }\end{array}$ \\
\hline fillosofía
\end{tabular}

Fuente: editorial Voluntad

El texto de Pensemos $10^{\circ}$ y Pensemos $11^{\circ}$, de Editorial Voluntad contribuyen al desarrollo de la Filosofía, con la propuesta de temas para los dos grados de la Educación Media.

Imagen 3. Libros de Filosofía

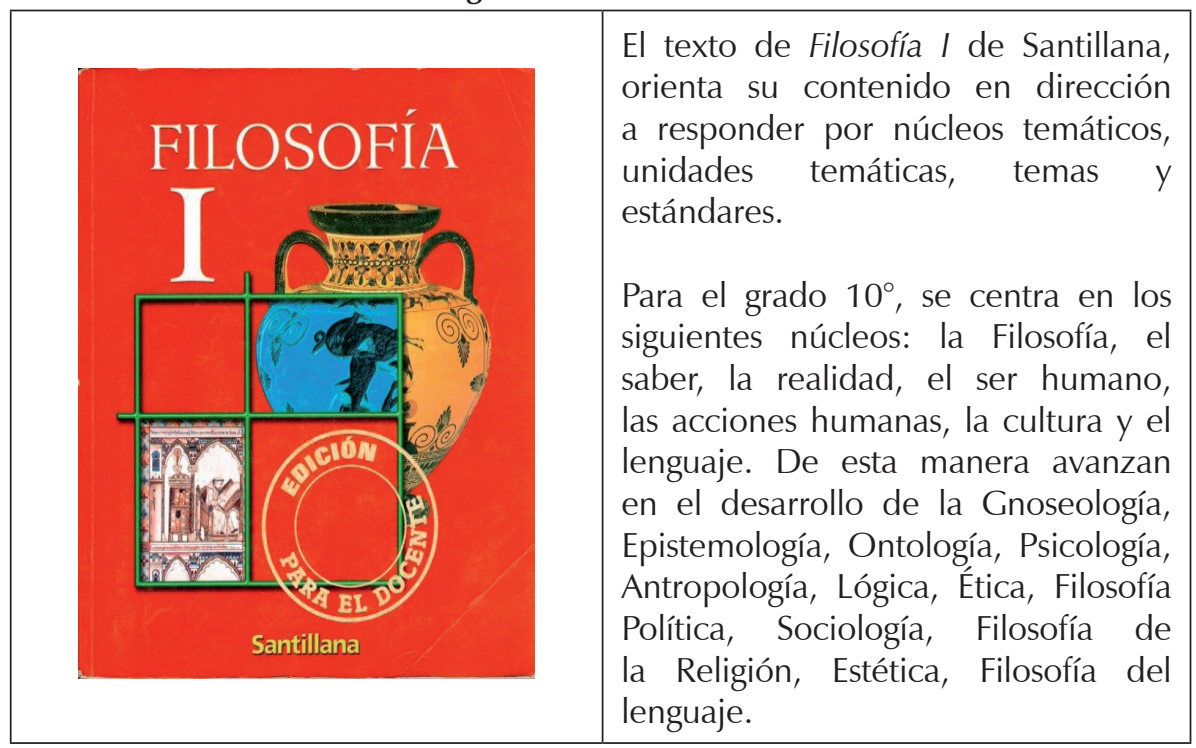

Fuente: editorial Santillana

Los textos de editorial Santillana entrelazan los núcleos temáticos, las unidades, los temas y los estándares de manera que lleve a un desarrollo eficiente de la temática y por ende al proceso de enseñanza. 
Imagen 4. Libro de Filosofía

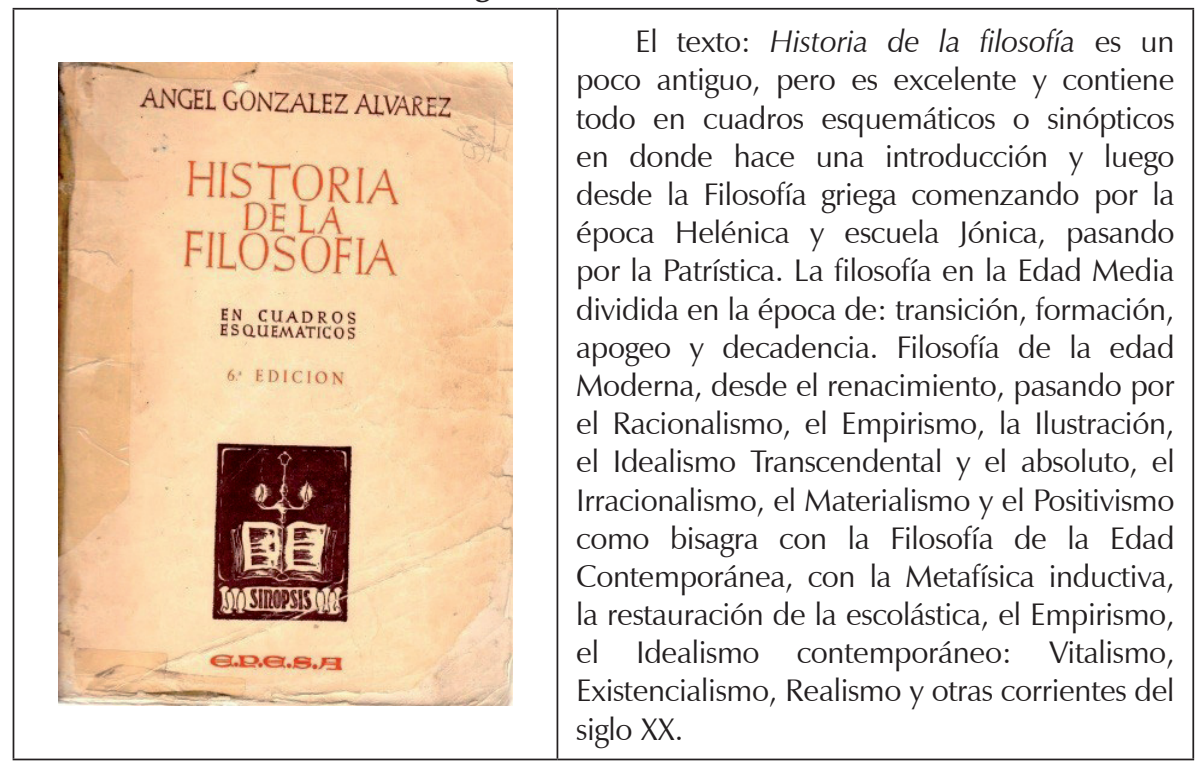

Fuente: editorial EPESA

El libro de Historia de la Filosofía en cuadros esquemáticos brinda una excelente oportunidad a docentes y estudiantes para afianzar de manera conceptual pero a la vez didáctica y sólida lo que significa el recorrido por las diferentes épocas y escuelas de la Filosofía, desde la Helénica hasta el siglo XX, contribuye a la dinamización del proceso de enseñanza-aprendizaje.

Imagen 5. Libros de Filosofía

\begin{tabular}{|l|l|} 
El libro PIENSO I... Filosofía y su historia, \\
corresponde al grado décimo y contiene \\
los siete centros de interés: \\
primero: introducción a la Filosofía, \\
segundo: Cosmología, tercero: \\
Ontología, cuarto: Antropología, quinto: \\
Lógica, sexto: Teoría del conocimiento, \\
séptimo: Historia de la Filosofía I, \\
Filosofía oriental, grecorromana, \\
medieval y moderna. \\
Contiene evaluación por competencias, \\
profundización filosófica y síntesis de \\
cada centro de interés.
\end{tabular}




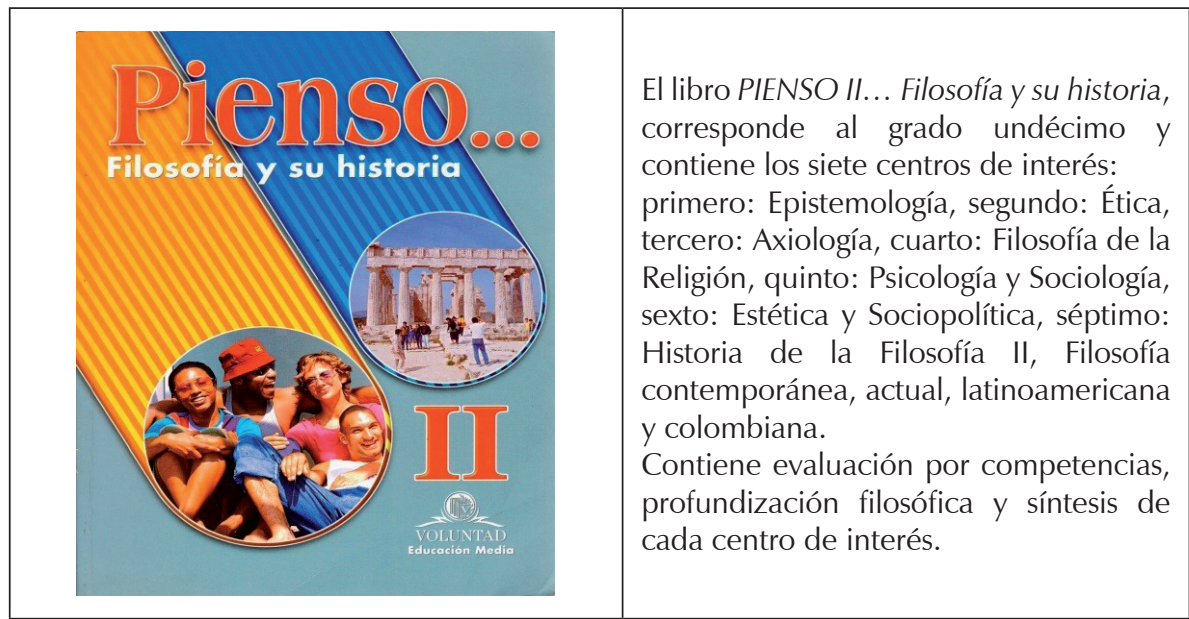

Fuente: editorial Voluntad

En la experiencia docente, se ha tenido más afinidad con los textos Pienso I y II de la editorial Voluntad que han permitido el óptimo desarrollo de la Filosofía. La selección de las obras referenciadas anteriormente obedece a muchas razones entre las cuales se destaca: revisión de bibliografía, textos frecuentes en las bibliotecas de las instituciones educativas de bachillerato, bancos de libros, posibles de adquirir por parte de los estudiantes, soporte de los planes de estudio, ayuda frecuente y permanente a los docentes.

\section{3. Tercera parte: propuesta metodológica para la enseñanza de la Filosofía}

La tercera parte de la propuesta induce a verificar los recursos, medios o ayudas didácticas que se pueden implementar para la enseñanza de la Filosofía y, en especial, de la Historia de la Filosofía. Por ello los recursos didácticos contribuyen a: "apoyar la exposición verbal del docente, consolidar el aprendizaje de conocimientos asociando imagen y concepto, frecuentando conceptos claves o realizando resúmenes y activar la participación de los alumnos" (Corrales, 2008, p. 189). La elaboración de los recursos didácticos pueden ser diseñados y elaborados por el profesor, profesionales o los estudiantes; lo importante es la construcción de conocimiento a través del desarrollo de los recursos didácticos.

Recursos didácticos probables de implementar: se requiere hacer un estudio de interrelación coherente entre el plan de estudios, el docente, el estudiante, los materiales y la metodología; lo importante es la sintonía ente los diferentes actores del proceso de enseñanza-aprendizaje, "planes de estudio, programas, organización y material, por muy importantes que sean, de poco o nada valen si no son vivificados por la personalidad dinámica del profesor" (Gómez, 1997, p. 276). 
Figura 10. Recursos didácticos

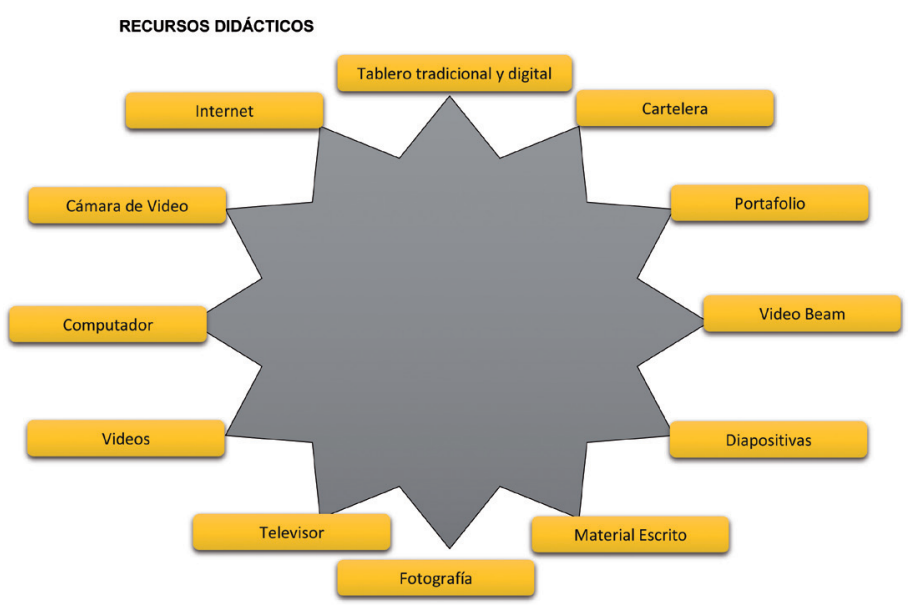

Fuente: elaboración propia

Organizadores gráficos: en la planeación de las clases, los recursos contribuyen a facilitar la aprehensión de diversos temas del desarrollo de la Historia de la Filosofía; en donde se pueden reconocer a los organizadores gráficos: mapas conceptuales, líneas del tiempo, esquemas conceptuales, mapas mentales, mapas de ideas, cuadros sinópticos, flujogramas, organigramas, histogramas, hexagramas, facilitando el quehacer del proceso enseñanza-aprendizaje.

Figura 11. Organizadores gráficos

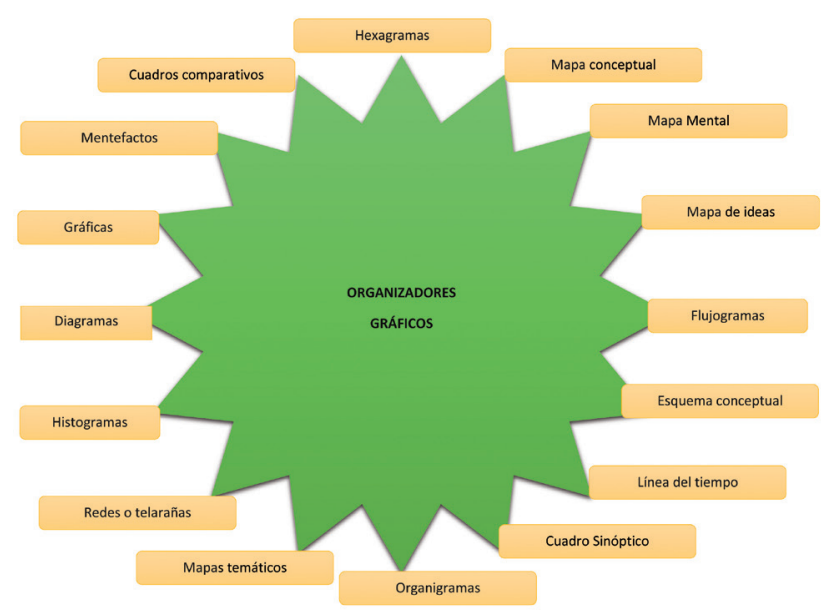

Fuente: elaboración propia 


\section{Recursos didácticos implementados para la enseñanza de la Filosofía}

Dada la formación filosófica y pedagógica, se comparten los avances de la propuesta que se está implementando para la enseñanza de la Filosofía y, especialmente, de la Historia de la Filosofía. La forma con la cual se quiere que la Filosofía sea más lúdica y dinámica es por medio de juegos que ejerciten la mente y le permitan desarrollar mucho más el nivel intelectual en los estudiantes. Algunos de los recursos enunciados son:

Parqués filosóficos: consiste en llegar a ser el ganador pero con una serie de acertijos que se deben resolver para lograr que la mente se ejercite aún más y se logren los conceptos.

¿Quién soy yo? filosófico: en este juego la idea principal es lograr descubrir todos los personajes que tiene el contrincante con la descripción de sus filosofías.

Lotería filosófica: se juega de manera que todos los contrincantes logren ocultar o encontrar todos los filósofos que se plasma en las imágenes y el primero que logre acumular todas las imágenes de su tablero será el ganador.

Tasos filosóficos: se encuentran plasmada las imágenes de grandes filósofos de toda la historia.

Monopolio y tío rico filosófico: tiene como principal interés adquirir la mayor parte en terreno donde vivieron los filósofos.

Twister filosófico: presenta imágenes en el tapete y en el tablero para que ubique la parte del cuerpo que te corresponda en la imagen indicada.

Ajedrez filosófico: consiste en fichas con imágenes de los filósofos más destacados de todos los tiempos se desplazan con el movimiento original del "ajedrez" ocupando las casillas correspondientes.

Filósofo lo sabes todo: trata de unas fichas en la cuales hay preguntas de todas las edades de la Filosofía que deben ser resueltas bajo las siguientes condiciones: si caes en una pregunta que te dan la sexta parte de la torta y las respondes, las tomarás, el fin es lograr tenerlas todas para determinar quién fue el ganador.

Póker filosófico: en vez del póker común se aplica a un póker filosófico, el cual tendrá en cada carta la imagen de los filósofos más importante de cada época. En donde se emplea el pensamiento para lograr ser el mejor de todos los contrincantes. 
Lotería filosófica: se elaboran los cartones de filósofos de diferentes épocas. También se tienen en cuenta otros recursos como: álbum filosófico, maquetas, diccionario filosófico, bingo filosófico, boletín filosófico, escalera filosófica, dominó filosófico, vídeos y exposiciones.

Se pueden evidenciar algunos materiales que se han convertido en estrategias para fortalecer la tradición filosofía y abren las puertas a la disertación oral y escrita de la misma. En un binomio la elaboración de un parqués y un álbum de filósofos, donde en cada una de las cuatro esquinas del parqués son las cuatro épocas principales de la filosofía con sus pensadores principales.

Imagen 6. Parqués y álbum filosófico

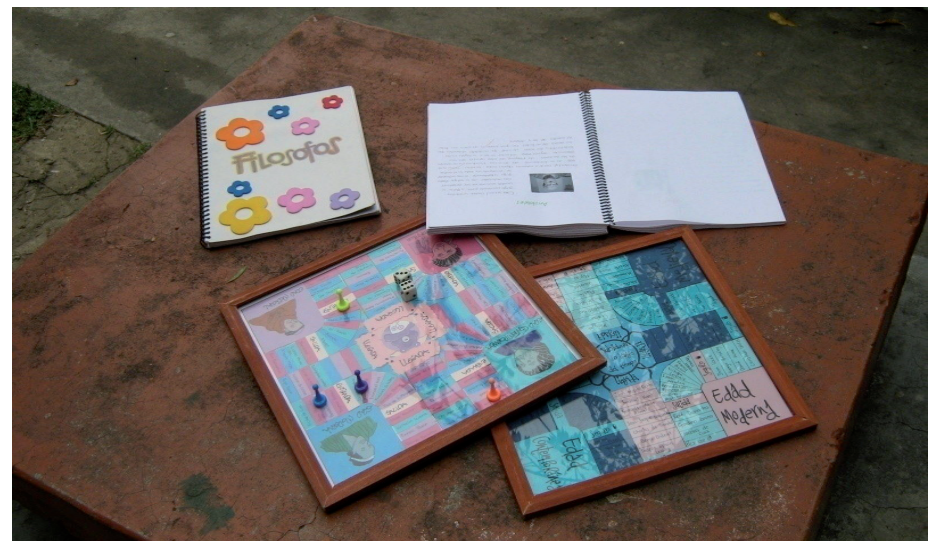

Fuente: estudiantes de grado $10^{\circ}$ y $11^{\circ}$

Otros materiales pueden ser los siguientes: mapas conceptuales, exposiciones orales, estrategias de aprendizaje cooperativo, basado en problemas, en proyectos, por indagación, para acceder a la esencia de Filosofía, el dialogar en sí mismo, desde su originalidad para tratar problemas de la realidad y proponer soluciones a problemas reales y de conocimiento.

De igual manera, se hace posible desarrollar actividades como sopas de letras, desarrollo de un foro, un panel, protocolo, póker, crucigrama, mentefacto, vídeo, cuadro sinóptico, ensayo, exposición, álbum, boletín escalera, bingo, boletín, esculturas, entre otras de carácter filosófico. Se observa una lotería y un periódico filosófico como ejemplo, todas están destinadas a fortalecer el aprendizaje de la tradición filosófica de acuerdo a cada una de las épocas de la misma y de paso filosofar, dialogar con los pensadores, con sus propuestas de pensamiento, con el fin de fortalecer un bagaje intelectual y las competencias argumentativas, interpretativas y propositivas donde se pueda responder a la vez a las pruebas estandarizadas del país, pruebas Saber $11^{\circ}$. 


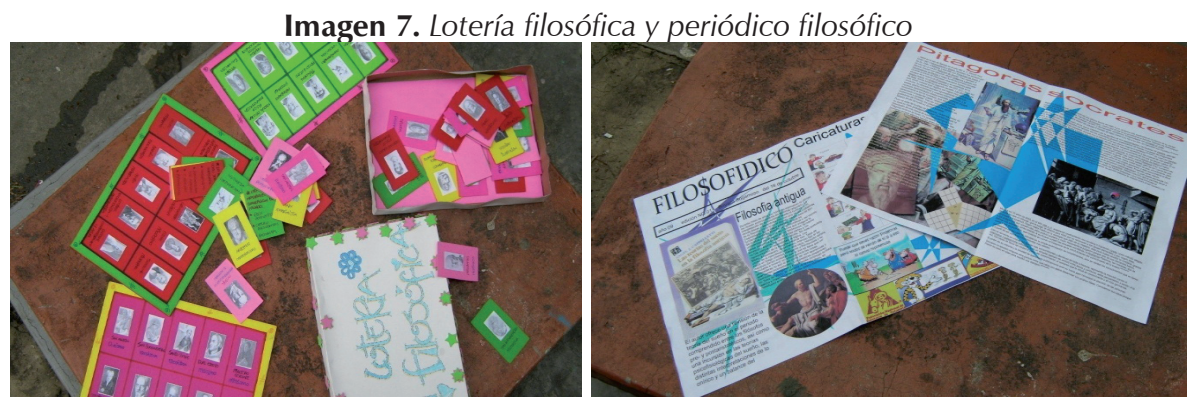

Fuente: estudiantes de grado $10^{\circ}$ y $11^{\circ}$

Para diseñar e implementar estas estrategias para enseñar y aprender Filosofía se requiere de un amplio bagaje sobre Didáctica. Sobre todo, si se tiene en cuenta que "la didáctica en filosofía es compleja y con muchos puntos de enfoque, por esta razón metafóricamente se la compara con un laberinto que tiene que resolver aspectos sicológicos sobre las condiciones cognoscitivas..." (Benavides, 209, p.105). Frente a este nudo que resolver se hace necesario discurrir con las estrategias para enseñar y aprender Filosofía y a filosofar en un mundo contemporáneo.

La siguiente tabla evidencia la Historia de la Filosofía en las cuatro grandes épocas, se constituye en insumo para la elaboración del parqués filosófico, el álbum filosófico y para la elaboración de otras estrategias didácticas en la aprehensión de la Historia de la Filosofía de una forma amena.

La creatividad por parte de los estudiantes es tan desbordante, que solo es necesario una dosis de motivación, buenas orientaciones y explicaciones de cada tema con el insumo de apoyo, al igual que el resultado que se espera que por lo demás ellos presentan y el ingenio que deslumbra al docente y lo importante es que ellos con sus propias palabras sustentan el trabajo realizado.

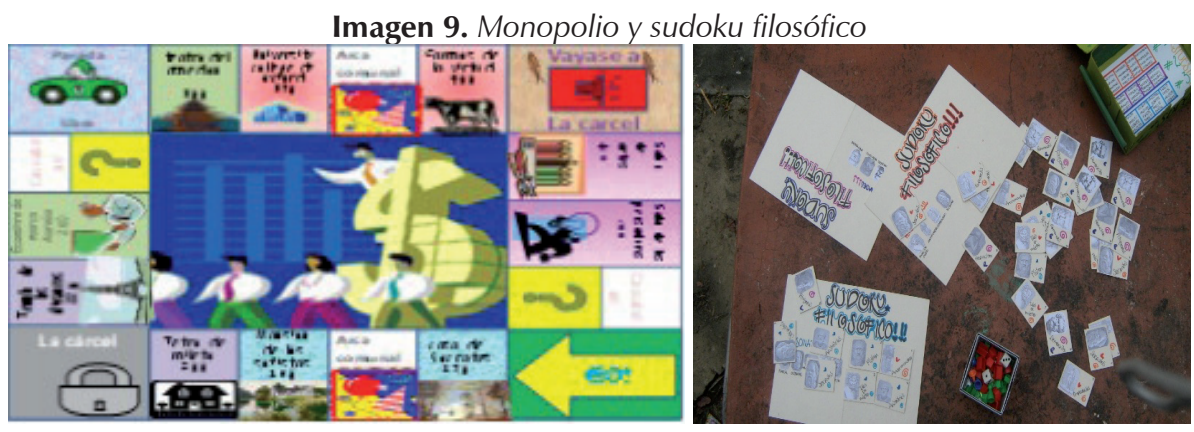

Fuente: estudiantes de grado $10^{\circ}$ y $11^{\circ}$ 
Se han presentado algunos de los trabajos propios de los estudiantes de Filosofía en la Educación Media sin descuidar los demás que han contribuido a mejorar sus argumentos y conocimientos de cultura general y cultura filosófica para un buen filosofar en su vida académica y posteriormente en la educación superior.

\section{Trabajo de campo}

Se aplicó una encuesta a 78 estudiantes con la finalidad de proyectar nuevas estrategias didácticas en la enseñanza de la Filosofía, con el objeto de fortalecer la formación integral. Se aplicó un instrumento diseñado para constatar sobre las ayudas didácticas para aprender. El instrumento diseñado corresponde a una encuesta con base en los elementos que componen una estrategia didáctica de mejoramiento para la formación filosófica de los estudiantes de Educación Media de un colegio privado a fin de cualificar su aprendizaje y su formación integral.

\section{1. Descripción, análisis e interpretación de resultados}

La encuesta se aplicó a setenta y ocho estudiantes (78), de grados décimo y undécimo, como se evidencia a continuación y que inicia con información sociodemográfica:

Gráfica 1. ¿Con quién vive?

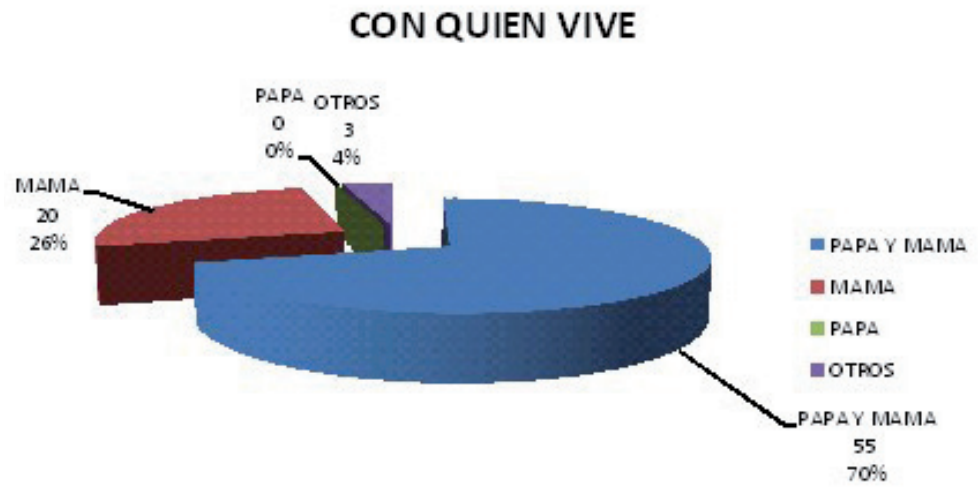

Fuente: encuesta aplicada a 78 estudiantes de Educación Media

De acuerdo con esta información la mayoría de los estudiantes (70\%) vive con ambos padres de manera adecuada, con el núcleo familiar papá y mamá. 
Gráfica 2. ¿Cuántos hermanos tiene?

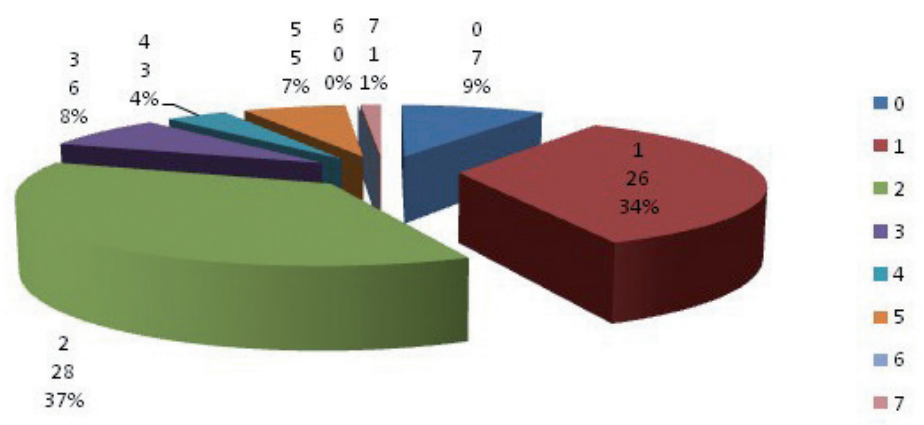

Fuente: encuesta aplicada a 78 estudiantes de Educación Media

Los datos que predominan son de 1 (26\%) y 2 hermanos (37\%). De tres y más hermanos se ocupa el (37\%).

Gráfica 3. Frecuencia con la que se utilizan ayudas didácticas en el proceso de enseñanza aprendizaje de la Filosofía

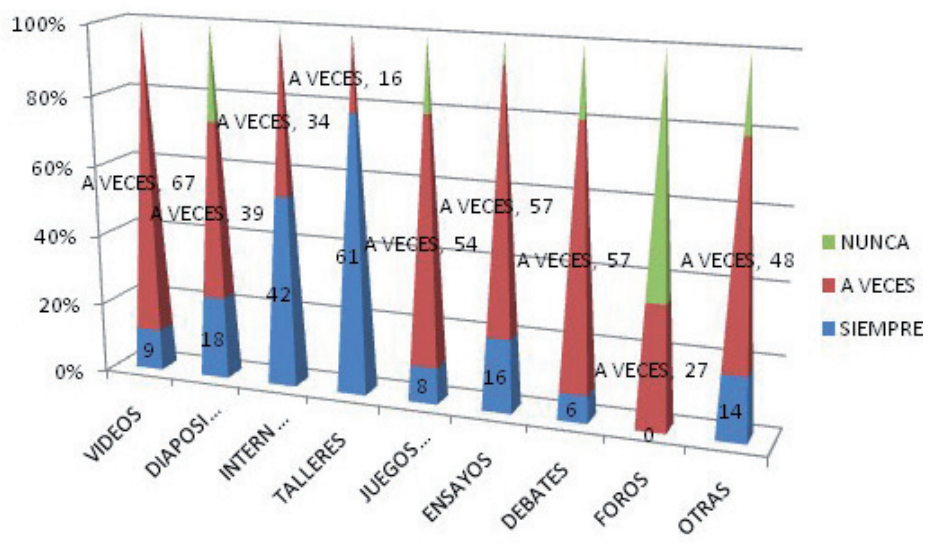

Fuente: encuesta aplicada a 78 estudiantes de Educación Media

El punto fuerte son los vídeos 95\% y los talleres 95\%, también la internet se usa un $60 \%$ siempre; se tendría que mejorar en lo concerniente a foros, ocupa el $30 \%$ a veces y $70 \%$ nunca y debates entre a veces y nunca $80 \%$ y siempre $20 \%$. 
Gráfica 4. ¿Cuál es la frecuencia de uso de los siguientes apoyos didácticos en su proceso escolar en Educación Media?

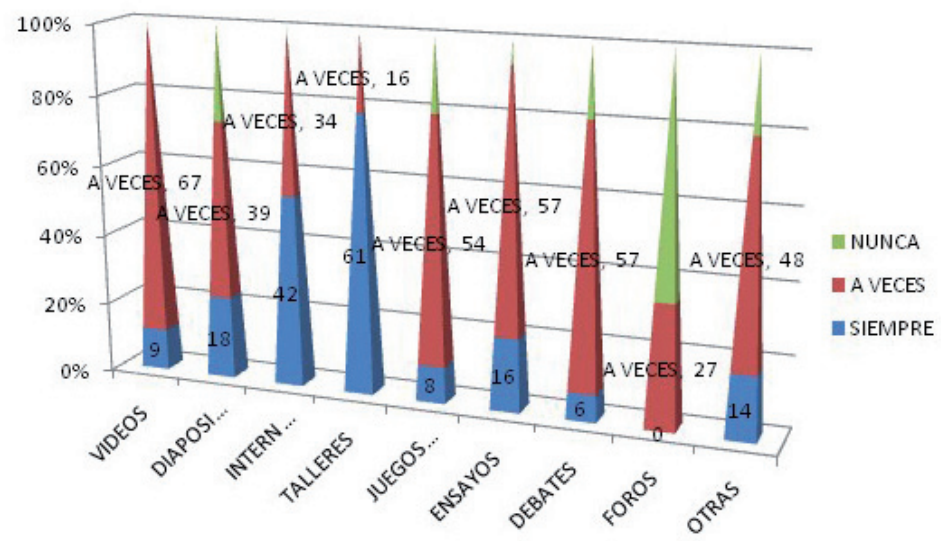

Fuente: encuesta aplicada a 78 estudiantes de Educación Media

De los apoyos más utilizados están los talleres con 78\% de siempre y el $22 \%$ a veces. Seguido de la internet con el 55\% siempre y $45 \%$.

Gráfica 5. ¿Cuál es el grado de pertinencia de las siguientes estrategias didácticas en su aprendizaje de la Filosofía?

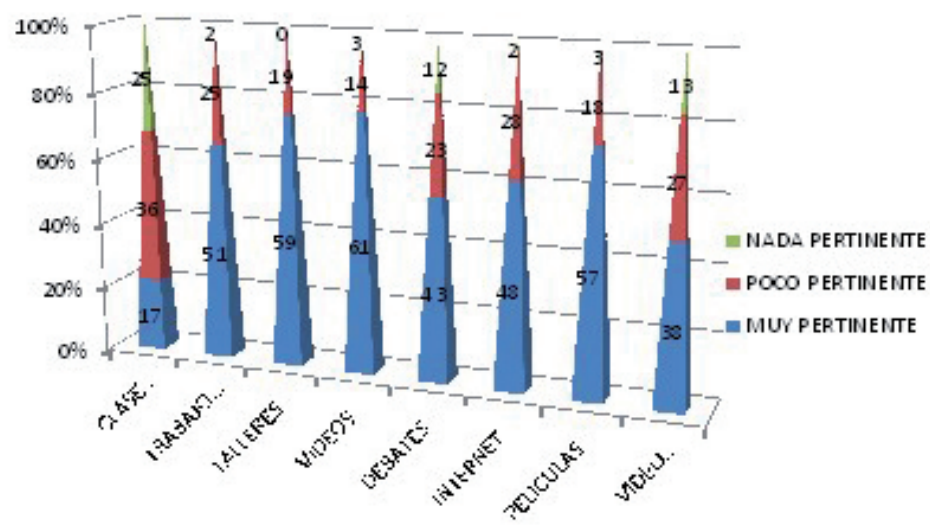

Fuente: encuesta aplicada a 78 estudiantes de Educación Media

Los estudiantes prefieren los medios audiovisuales para su aprendizaje, ocupa el $78 \%$ los vídeos seguido de las películas con un $76 \%$ y de los talleres con un $75 \%$, como muy pertinentes. 
Gráfica 6. ¿Cómo considera las clases de Filosofía hasta ahora?

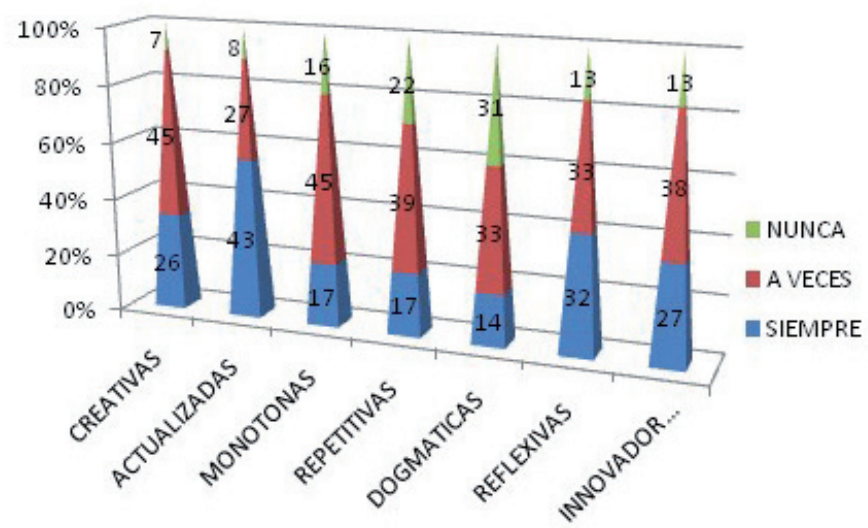

Fuente: encuesta aplicada a 78 estudiantes de Educación Media

En este punto nos damos cuenta que los estudiantes consideran que las clases son buenas y actualizadas un 55\%, reflexivas 38\% e innovadoras 34\%, aunque en algunos puntos se deben mejorar, por lo que son consideradas por algunos estudiantes repetitivas 14\%, monótonas $17 \%$ y dogmáticas $17 \%$, entonces se tiene que mejorar en este punto.

Gráfica 7. ¿A qué le atribuye las dificultades en el aprendizaje de la Filosofía?

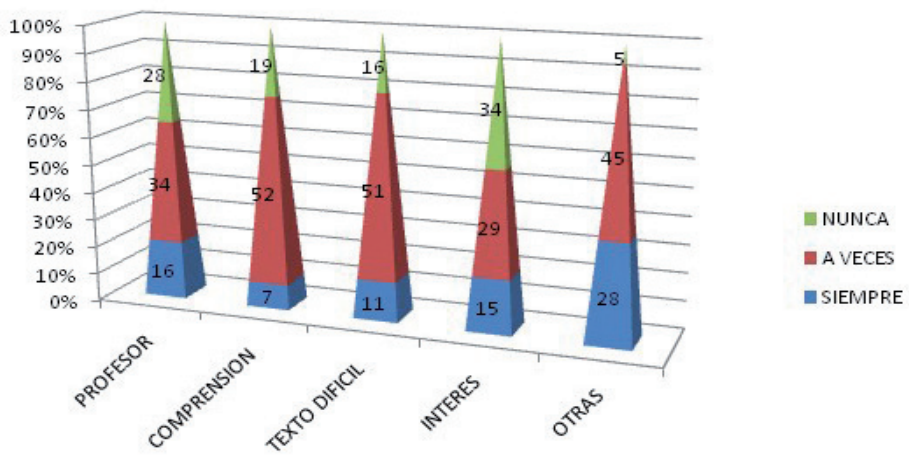

Fuente: encuesta aplicada a 78 estudiantes de Educación Media

Los estudiantes atribuyen sus dificultades primordialmente al texto difícil 75\% y a la falta de comprensión de la materia $70 \%$. Un 60\% a otras dificultades, al igual que se denota una gran dificultad en otras opciones diferentes a las señaladas y el propósito es descubrirlas. Expresan algún grado de dificultad con el profesor el $40 \%$ y del interés el $30 \%$. 
Gráfica 8. ¿Qué estrategias didácticas se utilizan en las clases de Filosofía?

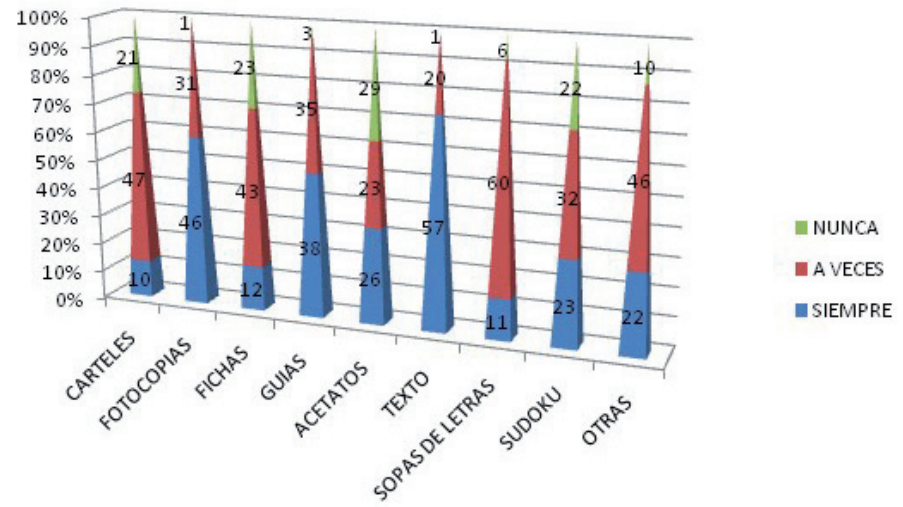

Fuente: encuesta aplicada a 78 estudiantes de Educación Media

Se tiene que mejorar en este punto ya que el principal apoyo de la clase son las fotocopias $55 \%$, texto $70 \%$, guías el $40 \%$, a veces las sopas de letras $80 \%$ y los carteles $60 \%$. Se deben implementar otras técnicas de apoyo para hacer más amena la clase. Algunos expresan que nunca se ha utilizado acetatos $30 \%$, sudoku $20 \%$ y carteles $22 \%$.

Gráfica 9. ¿Cuáles estilos de aprendizaje considera que se desarrollan más en el estudiantes de Educación Media desde la Filosofía?

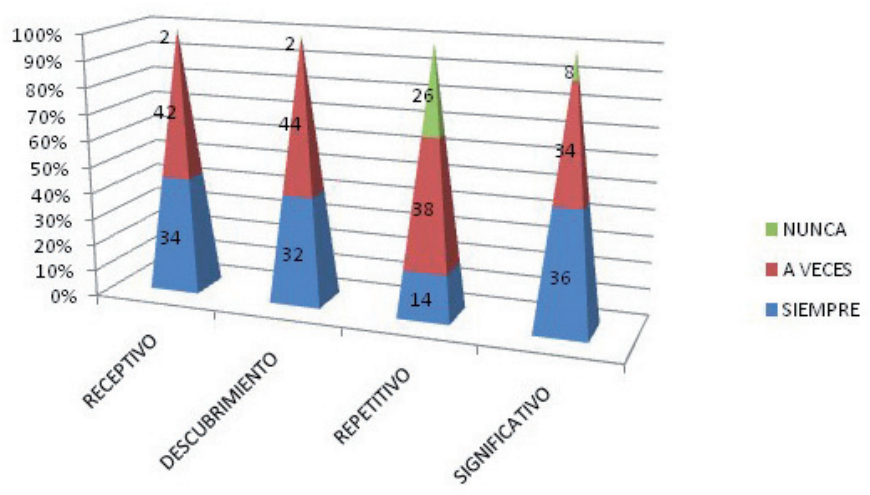

Fuente: encuesta aplicada a 78 estudiantes de Educación Media

En este punto nos encontramos bien, se desarrolla más el significativo $40 \%$, receptivo $35 \%$ y el de descubrimiento $32 \%$, ya que el aprendizaje está definido en distintos estilos y el estudiante podrá así identificarse con alguno y hacer así más fácil su aprendizaje. Una gran controversia con el aprendizaje repetitivo el 10\% dice que el utilizado, a veces 50\% y nunca $30 \%$. 
Gráfica 10. ¿Cuál de las competencias presenta mayor desarrollo en las clases de Filosofía?

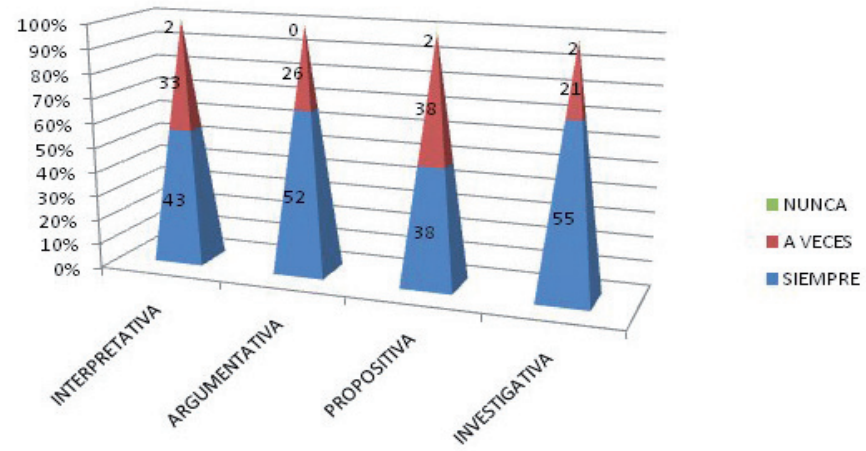

Fuente: encuesta aplicada a 78 estudiantes de Educación Media

Se están utilizando todas las competencias analizadas (investigativa 65\%, argumentativa $60 \%$, interpretativa $50 \%$ y propositiva $40 \%$ ) según los estudiantes, predomina la investigativa. Se demuestra en la gráfica que no expresan en algún momento que no se utilice alguna competencia y algunas veces expresan que son utilizadas las competencias pero en menor proporción.

Gráfica 11. ¿Cuáles de las siguientes ayudas didácticas son apropiadas para el desarrollo de la prueba Saber $11^{\circ}$ ?

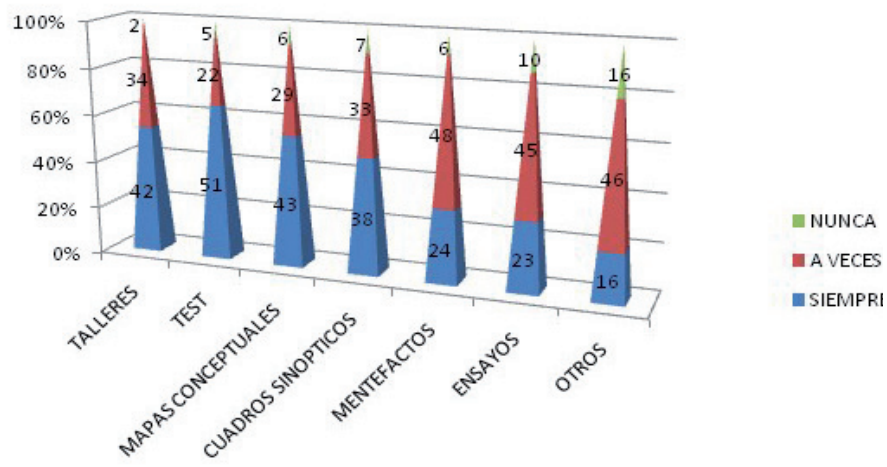

Fuente: encuesta aplicada a 78 estudiantes de Educación Media

La principal ayuda en los estudiantes para sus pruebas Saber $11^{\circ}$, según la encuesta fueron los test $60 \%$, aunque los talleres $50 \%$ y los mapas conceptuales $50 \%$ también les fue de ayuda y las otras ayudas tenidas en cuenta fueron importantes también para ellos, como cuadros sinópticos 40\%, mentefactos y ensayos 23\%. El 10\% expresa que nunca se ha utilizado ensayos y otras ayudas. 


\section{Análisis e interpretación de datos del trabajo de campo}

Una vez se ha hecho el diagnóstico pertinente en nivel de Educación media, en los grados décimo y undécimo, diagnóstico realizado a través de una encuesta de 10 preguntas, cada una con varias opciones, convirtiéndose estas en las variables respectivas para analizar. Se pretende conocer los estilos de aprendizaje de los estudiantes de Educación Media y plantear una estrategia didáctica consolidada para la formación filosófica de ellos, de tal forma que se responde a los objetivos propuestos, tanto general como específicos, por tal razón la información que se puede extraer de la encuesta permite ser corroborada en contraste de variables respectivamente.

De acuerdo a la tabulación y las gráficas, podemos tener en cuenta que el punto fuerte son los vídeos y los talleres, que se tendría que mejorar en lo concerniente a foros y debates. De acuerdo a esto, nos podemos dar cuenta que el punto fuerte son los vídeos 95\% y los talleres 95\%, también la internet se usa un $60 \%$. Se tendría que mejorar en lo concerniente a foros, ocupa el 30\% a veces y $70 \%$ nunca y debates entre a veces y nunca $80 \%$ y siempre $20 \%$. De los apoyos más utilizados están los talleres con $78 \%$ de siempre y el $22 \%$ a veces. Seguido de la internet con el 55\% siempre y $45 \%$.

La encuesta demuestra la necesidad de diseñar una propuesta pedagógica y didáctica que permita innovar con los foros, debates y muchas ayudas lúdicas didácticas. Por ello, los estudiantes prefieren los medios audiovisuales para su aprendizaje y poco las clases magistrales y monótonas. Los estudiantes consideran pertinente para el aprendizaje de la Filosofía los vídeos en un alto grado de efectividad seguido de los talleres, películas, trabajos en grupo y apoyados en la consulta de la internet. Los estudiantes prefieren los medios audiovisuales para su aprendizaje, ocupa el 78\% los vídeos, seguido de las películas con un 76\% y de los talleres con un $75 \%$, como muy pertinentes.

En este punto nos damos cuenta de que los estudiantes consideran que las clases son buenas y actualizadas un 55\%, reflexivas 38\% e innovadoras 34\%, aunque en algunos puntos se deben mejorar. Por ello, son consideradas por algunos estudiantes repetitivas por un $14 \%$, monótonas por un $17 \%$ y dogmáticas por un $17 \%$, entonces se tiene que mejorar en este punto. Se refleja en los estudiantes de educación media que atribuyen sus dificultades primordialmente al texto difícil y a la falta de comprensión de la materia. Se considera que las dificultades para el aprendizaje de la Filosofía están en otras posibilidades a las que se sugieren. Realmente genera duda e incertidumbre qué puede ser lo que hace difícil el aprendizaje de la filosofía. 
Se desarrolla más el significativo $40 \%$, receptivo $35 \%$ y el de descubrimiento $32 \%$ ya que el aprendizaje está definido en distintos estilos y el estudiante podrá así identificarse con alguno y hacer así más fácil su aprendizaje. Una gran controversia con el aprendizaje repetitivo, el 10\% dice que es utilizado a veces $50 \%$ y nunca $30 \%$. Está en un alto porcentaje de a veces: la comprensión de la asignatura, el texto difícil y otras que también se desconoce cuáles pueden ser otras de las dificultades que existen en la vida académica y el aprendizaje de la filosofía en los estudiantes de Educación Media.

Los estudiantes atribuyen sus dificultades primordialmente al texto difícil 75\% y a la falta de comprensión de la materia $70 \%$, un $60 \%$ a otras dificultades, al igual que se denota una gran dificultad en otras opciones disímiles a las señaladas y el propósito es descubrirlas. Expresan algún grado de dificultad con el docente el $40 \%$ y del interés el $30 \%$. Entre las ayudas didácticas se tiene que mejorar en este punto ya que el principal apoyo de la clase son las fotocopias 55\% y texto $70 \%$, guías el $40 \%$, a veces las sopas de letras $80 \%$ y los carteles $60 \%$, se deben implementar otras técnicas de apoyo para hacer más amena la clase. Y algunos expresan que nunca se ha utilizado acetatos $30 \%$, sudoku $20 \%$ y carteles $22 \%$.

Para los estudiantes, el aprendizaje que más han desarrollado en la educación media desde la Filosofía ha sido el significativo 40\%, receptivo 35\% y el de descubrimiento $32 \%$, ya que el aprendizaje está definido en distintos estilos y el estudiante podrá así identificarse con alguno y hacer así más fácil su aprendizaje.

Una gran controversia con el aprendizaje repetitivo el $10 \%$ dice que es utilizado a veces $50 \%$ y nunca $30 \%$. Se están utilizando todas las competencias analizadas (investigativa 65\%, argumentativa $60 \%$, interpretativa $50 \%$, propositiva $40 \%$ ) según los estudiantes, predomina la investigativa. La encuesta aporta que los test en un $60 \%$, talleres $50 \%$ y los mapas conceptuales $50 \%$ también les fue de ayuda.

\section{A manera de conclusiones}

La Filosofía requiere de la comprensión de las generalidades de la Pedagogía, Educación y Didáctica como elementos que permiten adentrarse en el proceso comprensión de una dinámica en el proceso de enseñanza-aprendizaje de la asignatura de Filosofía en la Educación Media.

El papel de profesor que orienta la asignatura de Filosofía es importante en la medida en que es él quien ha de dinamizar el proceso educativo; pero el docente de Filosofía ha de contar con una serie de cualidades generales y también específicas para que su labor la ejerza de verdad con vocación y compromiso social por aquellos que se la han encomendado para sembrarles la semilla del filosofar. 
La asignatura de Filosofía en la Educación Media es de igual o mayor importancia que las demás que hacen parte del plan de estudios; se orienta por norma según la Ley general de Educación 115 de 1994, es oportuna y contribuye con las demás al desarrollo integral del estudiante desde la perspectiva del desarrollo de las habilidades y facultades intelectuales propias del ser humano como ser racional.

El estudiante de Filosofía en la Educación Media es un adolescente, en nivel intermedio o superior; pero es, en realidad, la edad que sí es importante en el desarrollo humano, para el caso de la filosofía se entiende como una oportunidad de maduración para razonar desde el campo de la intuición y apoyado en los diversos métodos de la filosofía.

Los recursos didácticos para la enseñanza de la Filosofía son un medio de dinamizar el proceso educativo de manera que le sirven al profesor para dar a entender elementos complejos del desarrollo filosófico y al estudiante para la aprehensión de conceptos, autores y otros elementos propios de la filosofía y estar a la altura de filosofar con argumentos en cualquier campo de la vida.

Las propuestas que se han podido realizar llevan a que entre los docentes de Filosofía promuevan el amor por la Filosofía de manera amena para ellos y para los estudiantes, pues se reconoce que la enseñanza y también el aprendizaje no son fáciles pero que tampoco son difíciles en la medida que se apoya en la diversidad de recursos didácticos, sin descuidar los problemas filosóficos.

\section{REFERENCIAS}

Caicedo, Y. et al (2010). Pedagogía y Currículo. Seminario Permanente de Pedagogía. Tunja: Imprenta y publicaciones - UPTC.

Corrales, M. (2008). Metodología de la formación abierta y a distancia. Balderas: Editorial Limusa, S. A.

De la Torre, Z. (2009). 12 Lecciones de pedagogía, educación y didáctica. México: Editorial Alfaomega.

Gómez, M. (1997). Didáctica de la Filosofía. Santa Fe de Bogotá: Universidad Santo Tomas USTA.

González, A. (1969). Historia de la Filosofía: En cuadros esquemáticos. Madrid: Ediciones EPESA S. A. 
Islas, N. (2012). Didáctica Práctica: Diseño y preparación de una clase. México: Editorial Trillas.

Lucio, R. (2009). La gestión de la enseñanza y el aprendizaje. Seminario Permanente de Pedagogía. Tunja: Imprenta y publicaciones - UPTC.

Lozano, R. (2005). El éxito en la enseñanza. México: Editorial Trillas

Ley 115 de 08 de Febrero de 1994. Por la cual se expide la Ley General de Educación. Bogotá D. C. Colombia: Ediciones Momo.

Morales, G. et al (1999). Sé tú mismo, aprende a ser persona. Trabajo de grado para la especialización en docencia universitaria, Bogotá: Universidad Militar Nueva Granada.

Morales, B. (2006). Filosofía $10^{\circ}$ : Aprendiendo a filosofar con competencias. Bogotá: Editorial Paulinas

Morales, B. (2002). Filosofía $11^{\circ}$ : Aprendiendo a filosofar con competencias.

Bogotá: Editorial Paulinas

Páez, E. (2010). A propósito de la didáctica: Salir del aula, entrar al aula. Seminario Permanente de Pedagogía. Tunja: Imprenta y publicaciones - UPTC.

Ramón, A. (2006). 10 Claves de la Educación. México: Editorial Trillas.

Suárez, D. (2010). La educación. Estrategias de enseñanza - aprendizaje, teorías educativas. México: Editorial Trillas.

Suarez, M. (2003). Pienso... Filosofía y su Historia II. Bogotá: Editorial Voluntad. Educación Media.

Verano, G. (2004). Pienso... Filosofía y su Historia I. Bogotá: Editorial Voluntad. Educación Media. 